\title{
Critical raw materials and transportation sector electrification: A detailed bottom-up analysis in world transport Emmanuel HACHE ${ }^{a, b, c}$, Gondia Sokhna SECK ${ }^{a,{ }^{*}}$, Marine SIMOEN ${ }^{a}$, Clément BONNET $^{a}$, Samuel CARCANAGUE ${ }^{b}$
}

February, $5^{\text {th }} 2019$

\begin{abstract}
Integrated assessment models are generally not constrained by raw materials supply. In this article, the interactions between a wide diffusion of electric vehicles in the world transportation sector and the lithium supply are analysed in the Times Integrated Assessment Model (TIAM-IFPEN version). The lithium sector and a detailed representation of the transportation sector have been then implemented into the TIAM-IFPEN processes constituting the global energy system. Hence, the availability of this strategic material to supply the growing demand for low-carbon technologies in the context of the energy transition can be questioned. Incorporating an endogenous representation of the lithium supply chain allows investigating its dynamic criticality depending on several optimal technology paths that represent different climate and/or mobility scenarios between 2005 and 2050. It is the first detailed global bottom-up energy model with an endogenous disaggregated raw materials supply chain. Based on our simulations, the geological, geopolitical and economic dimensions of criticality are discussed. Four scenarios have been run: two climate scenarios $\left(4^{\circ} \mathrm{C}\right.$ and $\left.2^{\circ} \mathrm{C}\right)$ with two shapes of mobility each: a high mobility where we consider the impact of urban dispersal with a huge car dependence/usage, and a low mobility in which the demand for individual road transport is lower due to a more sustainable urban planning and more public transport. The electric vehicles fleet should reach up to $1 / 3$ of global fleet by 2050 in the $4^{\circ} \mathrm{C}$ scenarios, while it could be up to $3 / 4$ in the $2{ }^{\circ} \mathrm{C}$ scenarios both with high mobility, mostly located in Asian countries (China, India and other developing countries in Asia) due to the large presence of 2 and 3-wheelers. The penetration of electric vehicles has a major impact on lithium market. The cumulated demand over the period 2005-2050 reaches up to 53\% of the current resources in the $2{ }^{\circ} \mathrm{C}$ scenario with a high mobility. These results tend to show an absence of geological criticality. Nevertheless, they have clearly highlighted other different forms of vulnerabilities, whether economic, industrial, geopolitical or environmental. A discussion about the future risk factors on the lithium market is done at a regional scale aiming at analysing more in-depth the impact of the electric vehicle on lithium market. Our study of this particular strategic material shows that the model could be a useful decision-making tool for assessing future raw material market in the context of the energy transition and could be extended to other critical raw materials for more efficient regional and sectorial screening.
\end{abstract}

Keywords: World transportation; Electrification; Critical raw materials; Lithium; Bottom-up modelling JEL Classification: Q42, R40, C61

\footnotetext{
a. IFP Énergies Nouvelles, 1-4 av. de Bois Préau, F-92852 Rueil-Malmaison, France.

b. The French Institute for International and Strategic Affairs, (IRIS), France.

c. EconomiX-CNRS, University of Paris Nanterre, France.

* Corresponding author. Tel.: +33147525012

E-mail address: gondia-sokhna.seck@ifpen.fr
} 


\section{Introduction}

Technology is generally considered to be called to play a major role in the low-carbon energy transition, but large uncertainties remain about the widespread diffusion of low-carbon innovations [1], [2]. The cost, the speed of adoption and the acceptance of technologies by different stakeholders are thus fundamental parameters for drawing decarbonisation trajectories. What is given as a certainty with all decarbonisation innovations is the growing need for ores and refined metals [3]. Life-cycle assessments (LCAs) of individual technologies suggest that low carbon power plants tend to require more materials per unit than fossil fuelled plants [4]. Vidal [5] considers that the current available material reserves would certainly not be sufficient in a future driven by stringent environmental constraints and economic growth. Indeed, in the power sector for example, nearly $178 \mathrm{GW}$ of new renewable electricity generation capacities have been added in 2017 according to the IEA WEO 2018, representing nearly $60 \%$ of power generation capacity additions. Around $482 \mathrm{GW}$ are under construction or expected to 2020 (49\% of solar and $34 \%$ of wind) around the world. The multiple future pathways for global energy through to 2050 with existing policies and announced intentions around the world raise two questions: How these fast shifts can impact material resource availabilities? Would future possible constraints on supply of materials impede this energy transition?

Hache [6], [7] argued that the massive diffusion of low-carbon innovations, while reducing the dependencies to fossil fuels, would certainly lead to new and unexpected interdependencies including dependencies on raw materials. This is commonly referred to as "raw material criticality". Behind this term, there are many definitions and assessment methodologies used. For example, the European Commission has considered a raw material as critical, when "it must face high risks with regard to access to it, i.e. high supply risks or high environmental risks, and be of high economic importance. In such a case, the likelihood that impediments to access occur is relatively high and impacts for the whole EU economy would be relatively significant". Gleich et al. [8] have considered criticality as the extent of current and future risks associated with a certain metal. The concept of "criticality" in terms of raw materials has been introduced for the first time in 1939 with the so called "Critical Material Stock piling Act" by the US government to secure militarily relevant materials for which uncertainty on availability exist due to geopolitical context. The first direct study on critical materials has been introduced by the U.S. National Research Council [9] with its "criticality matrix approach" on the basis of two criteria: the economic importance of the resource and the supply risk. Most criticality studies follow an approach analogous to this 
classical risk assessment. Some analyses, such as the ones performed by Graedel et al. [10], also include an environmental impact axis in their assessments.

As an heterogeneous field of research, raw materials supply risk and criticality have been widely discussed since the past decade [11], [12], [13]. Since 2000, more than 2,000 articles, conference papers or "peer-reviewed" resources have been published on the issue of material criticality, nearly $80 \%$ of which since 2010 (Fig. 1).

Fig. 1 : Number of publications related to criticality

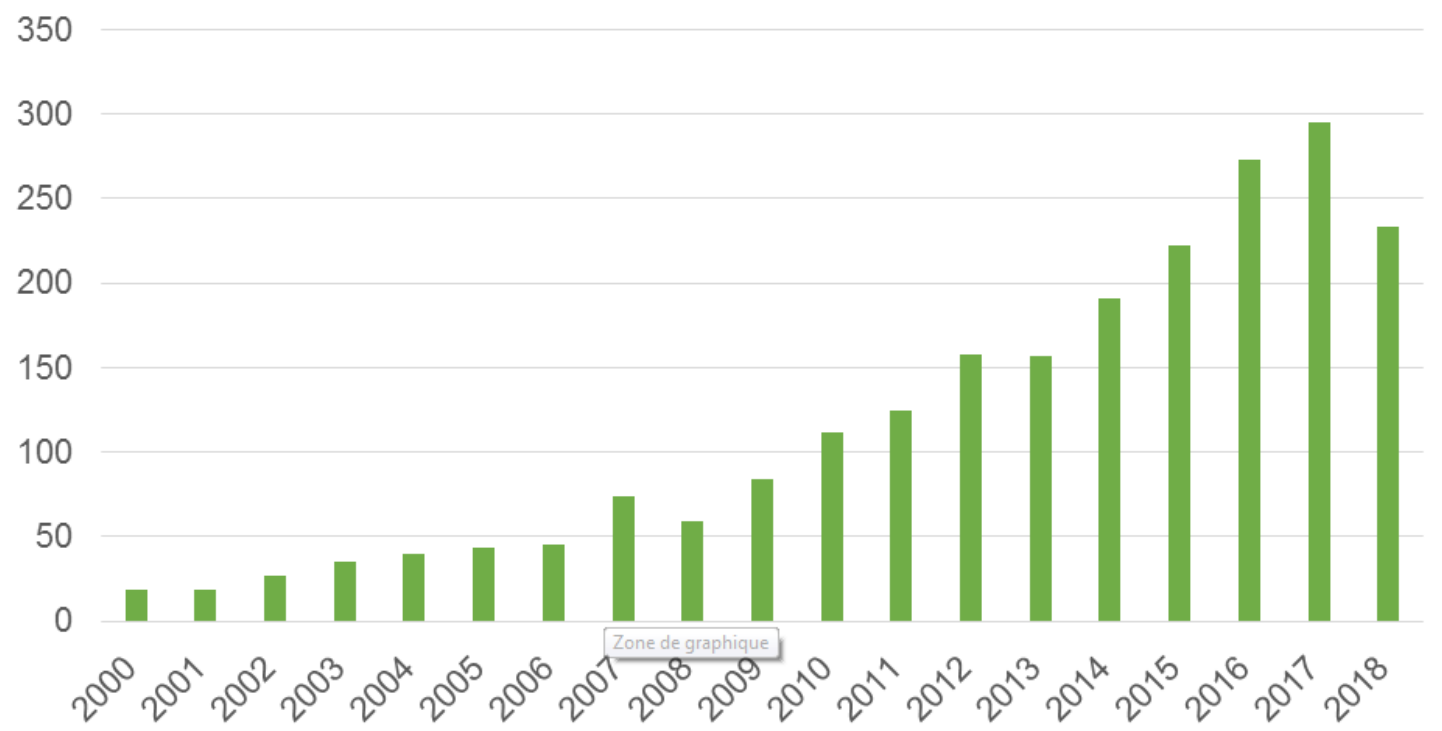

Source: Intellixir (For the year 2018, the research did not take into consideration articles published after June, 30th 2018) ${ }^{1}$

An extensive part of the first literature was devoted to rare-earth elements (REE) criticality although for few years increasingly number of metals are in the spotlight, even including nonferrous-metals. A certain number of authors such as Du \& Graedel [14] and Gooman [15] explored the global flows into use for rare earth metals and the in-use stocks worldwide, while Golev et al. [16] only focused on the assessment of non-Chinese primary and secondary REE suppliers and the potential of recycling to circumvent supply constraints. The assessment

\footnotetext{
${ }^{1}$ We conducted bibliometric analyses using the Intellixir statistics and text-mining software (Intellixir is a texmining tool used to perform statistical and bibliometric analyses on articles in the Scopus database (concepts used, origin of publications, collaboration links between authors and institutions, etc.). It make it possible to highlight the positioning and relationships between the different authors or institutions producing these researches, their geographical distribution and the concepts they deal with, etc. For this study, we selected the following peer-reviewed journals: Applied Energy, Energy Policy, Energy Economics, Energy Resources Policy, Science of The Total Environment, European Journal of Operational Research, Global Environmental Change, Journal of Cleaner Production, The Extractive Industries and Society, Ore Geology Reviews, Renewable and Sustainable Energy Reviews, Applied Energy, Resources, Conservation and Recycling, Journal of Rare Earths, Sustainable Materials and Technologies, Ecological Economics, Renewable Energy, Environment, Science and Technology
} 
methods, which have been applied to a wide range of raw materials, are mostly snapshot analysis in time with determined and relevant indicators that explain the differences, from year to year, in the list of raw materials considered critical [17]. The dimensions of interest considered are usually vulnerability and supply risk relying on economic [18], geological or technical concerns [19], [20] sometimes extended to cope with environmental impacts [21] or social implications [22]. Several methods relied on past supply disruption events [23] and possible future growth with constant past trends [24] or without including detailed studies of the development of emerging technologies, GDP forecasts, evolution and interactions between all sectors of the economy along with stringent environmental scenarios [25], [26]. Knowing and quantifying the implications of prospective energy scenarios for raw material resources would be valuable in order to shape the future with more efficient resource management. Thus, a need to better integrate raw material contents of all technologies considered in energy system models. Thus, long-term energy analyses without taking into account the adequate available resource supplies could be irrelevant or might need to be reassessed in response to new resource supply constraints. Energy system models normally do not consider the raw material life cycle inventories (LCIs) of energy technologies and are therefore not capable of answering the two questions above. A linkage between raw material sectors and prospective energy models has to be considered by energy system modellers and policymakers. In this perspective, two main strands of approach have been observed in the scientific literature. The first approach relies on using the outputs of long-term energy model or specific roadmapping process as inputs into prospective detailed life-cycle assessment analyses. Several studies are taking this approach and have then developed dynamic LCIs in line with the prospective scenario generated by energy system models or government's goals. Moss et al. have showed for example the potential limiting role of metals in the specific deployment of the European Union's Strategic Energy Technology Plan (SET-Plan, 2013) based on optimistic deployment-scenarios for 2020 and 2030 [27]. Roelich et al. have also quantified the criticality of neodymium focused on the roll-out of wind turbines for the UK low-carbon electricity scenario generated by the IEA ETP model, a bottom-up energy optimization model [28]. In that vein, Beylot et al. have quantified some raw material needs as a response to the French energy transition by 2050 (with a focus on power sector) based on prospective scenarios of the French National Alliance for the Coordination of Research for Energy (ANCRE) [29], while Boubault et al. [30] have quantified them using the TIAM-FR scenario outputs through to 2100 . Viebahn et al. [30] have pointed out the potential supply risks owing to material dependencies on a few supplier countries in the transformation of the German energy system towards more renewable sources. These studies have provided important insights into the relative importance of dynamic analysis of criticality in order to 
reduce the probability of 'locking-in' to technologies that are currently attractive but potentially critical for the future. For the second approach where the outputs of LCI metrics have been used as inputs into prospective energy models, fewer studies have been found in scientific literature. Three recent studies considered this approach, however, they were only covering environmental implications. They both incorporate indirect emissions derived from process-LCA [32], from an environmentally extended multiregion input-output (EE-MRIO) model [33] and from hybrid input-output based LCA [34] into TIMES models (of Norway, UK and Europe respectively). Thus, by considering raw material life-cycle metrics in an integrated assessment model, this paper contribute filling the gap identified in the literature on energy system optimization models. It will allow examining the risks related to the question of raw materials in the energy transition: geological risk, geopolitical risk, production risk, etc. through the first integrated raw material market in a global bottom-up energy model.

A complete lithium supply chain has been introduced and a lithium content per vehicle according to its size has been attributed, derived from the Ecoinvent database and our expertise. The technologies are part of the energy system optimization model, TIAM-IFPEN. We have developed the first detailed global bottom-up energy model with an endogenous representation of the lithium supply chain. This model is able to evaluate the dynamic criticality of lithium and other strategic materials depending on several optimal technology paths. There is, therefore, a dual advantage:

- The capacity to endogenously account for the impact of raw material resource constraints (resource availability, extraction cost), technical constraints (physical balances, availability factors, etc.) and non-technical constraints (market penetration limits, policy scenarios, environmental specifications, etc.) on the demand satisfaction or the roll-out of emerging low carbon technologies

- Dynamic assessment of raw materials criticality using the safety margin indicator. This indicator provides a linkage between the evolution of the cumulated raw material consumption and the available resource for a given period.

In this paper, the methodology developed has been applied to the study case of lithium due to a future increasing electrification of the transport which will induce a fast roll-out of electric vehicles in the coming years. Moreover, when comparing the lithium market to the definition of strategic metals given by Graedel et al. [35] and completed by Helbig et al. [36], lithium meets 5 out of the 7 under mentioned criteria:

(i) The metal is used in many industrial sectors;

(ii) It is difficult to find in the short term a suitable substitute for this metal for one or more industrial applications; 
(iii) The number of industrial applications using this metal is broad and increases over time;

(iv) The metal is used in dispersing applications with limited recycling potential;

(v) The metal has a great economic value;

(vi)The metal production and reserves are geographically concentrated;

(vii) The metal production could damage human health and/or ecosystem;

With more than 3 million electric vehicles $(\mathrm{EV})^{2}$ in circulation in the world in 2017 according to the Global EV 2018 [37] survey, 2017 continued the trend towards electrification that has existed since 2010. The market of electric passenger light-duty vehicles has increased 10-fold between 2011 and 2016, resulting in a significant increase of the lithium demand for the battery sector ( $+20 \%$ between 2012 and 2017 considering USGS database). In addition, more and more significant policies have been implemented at national scale, especially in China, the European Union and India to accelerate the deployment of electric cars on a global scale. Thus, the structure of the transportation sector is evolving and changing rapidly since few years. This structural evolution will have a strong impact on the lithium market. As a strategic metal for battery production, it is quite representative of the new challenges related to the energy transition due to the potential for electrification of vehicles worldwide, the concentration of reserves in a limited number of countries, the limited recycling potential and the oligopolistic industrial structure of its market [38]. Previous works have already been conducted on lithium criticality, mainly focused on estimating the future lithium demand [39], [40] with a large variety of time horizons from short-term [41] to mid-long term, until 2100 [42]. Future lithium volumes are mainly depending on the EV scale deployment and the average lithium content per vehicle. The evolution of the EV stock was mostly based on authors' assumptions or scenarios borrowed from the literature while the average lithium content was based on small car analysis. For example, Speirs et al. [43] based their estimation on the IEA Blue Map scenarios and used different material intensity to estimate the lithium demand. Most of these works underlined the potential absence of deep lithium depletion in the future in regards to its current resources or reserves. Yaksic \& Tilton [42] have for example previously addressed the threat of lithium depletion and concluded that there was possibly no issue on lithium supply till the end of the century, even in a $100 \%$ electric scenario by using the cumulative availability curve $^{3}$. Other research papers have laid

\footnotetext{
${ }^{2}$ Electric vehicles include battery electric vehicles (BEVs), plug-in hybrid electric vehicles (PHEVs) and fuelcell electric vehicles (FCEVs). In this article, our transport module covers passenger light duty vehicles (PLDVs), Light, Medium and Heavy Commercial Vehicles (LCVs, MCVs and HCVs), Buses, Minibuses and two- and three-wheelers.

${ }^{3}$ The cumulative availability curve shows the quantities of a mineral commodity that can be recovered under current conditions from existing resources at various prices.
} 
emphasis on lithium criticality with larger discussions than resources or reserves constraints insisting for example on the impact of recycling [44], [45] or battery technologies [46], including more and more economic concerns such as economies of scale [47]. Geopolitical dimension has also been discussed through global material flow analysis (MFA) [48], [49]. South America, and in particular Bolivia which has the largest resource of the region [50], were also widely spotlighted [51] by literature as important determinants of the lithium's criticality, as well as China the first lithium consumer [52]. Nonetheless lithium is also strategic regarding regions with potential future large demands while having no major resources, such as Europe, where recycling and substitution potentials were also analysed by Miedema \& Moll [53]. Finally, none of these works have considered a global threedimensional approach taking into account geological, geopolitical and economic criteria with the transport evolution and global environmental constraints.

With a high regional breakdown of the world, our TIAM-IFPEN model is particularly well suited to develop prospective exercises by 2050 using an integrated approach. Such an approach provides an opportunity to understand and discuss factors that may influence the evolution of the global transport sector, on which the lithium market may be highly dependent. The rest of the paper is organized as follows : Section 2 describes the methodology, the overall structure of the TIAM-IFPEN bottom-up model, and the specific features and assumptions engaged for a detailed lithium criticality analysis; Section 3 presents our main results and related analyses on the lithium market at global and regional levels, lithium resource availability and the implications for future road passenger transport mobility, finally Section 4 summarizes our findings and provides several policy recommendations regarding risks assessment of the lithium market.

\section{Methodology}

TIAM-IFPEN (TIMES ${ }^{4}$ Integrated Assessment Model) model [54], [55] is a technology rich bottom-up cost optimization belonging to the MARKAL ${ }^{5}$ family model [56], [57], [58]. Energy supply, demand and market dynamics are modelled in order to represent energy dynamics over a long-term, multi-period time horizon at a local, national, multi-regional, or global level. A detailed description of the model with its main features (technical, economic and policy parameters, scenarios...) is provided in the following subsections.

\subsection{Description of the TIAM-IFPEN model}

\footnotetext{
${ }^{4}$ The Integrated MARKAL-EFOM System

${ }^{5}$ MARKet Allocation model
} 
TIAM-IFPEN model, a bottom-up linear programming model, have been developed recently at IFP Energies Nouvelles (IFPEN). It is a version of the ETSAP ${ }^{6}$-TIAM model, developed in 1997 by one of the IEA implementing agreements IEA-ETSAP, which is the global incarnation of the TIMES model, the successor of the former generators MARKAL and $\mathrm{EFOM}^{7}$ [59], but implemented with new features for enlarging its field of application and providing greater flexibility. It is a global multiregional model simulating the dynamics of the global energy system from resource extraction to energy end-use over a long-term period of over 100 years.

Fig. 2: TIAM model’s Reference Energy System [60]

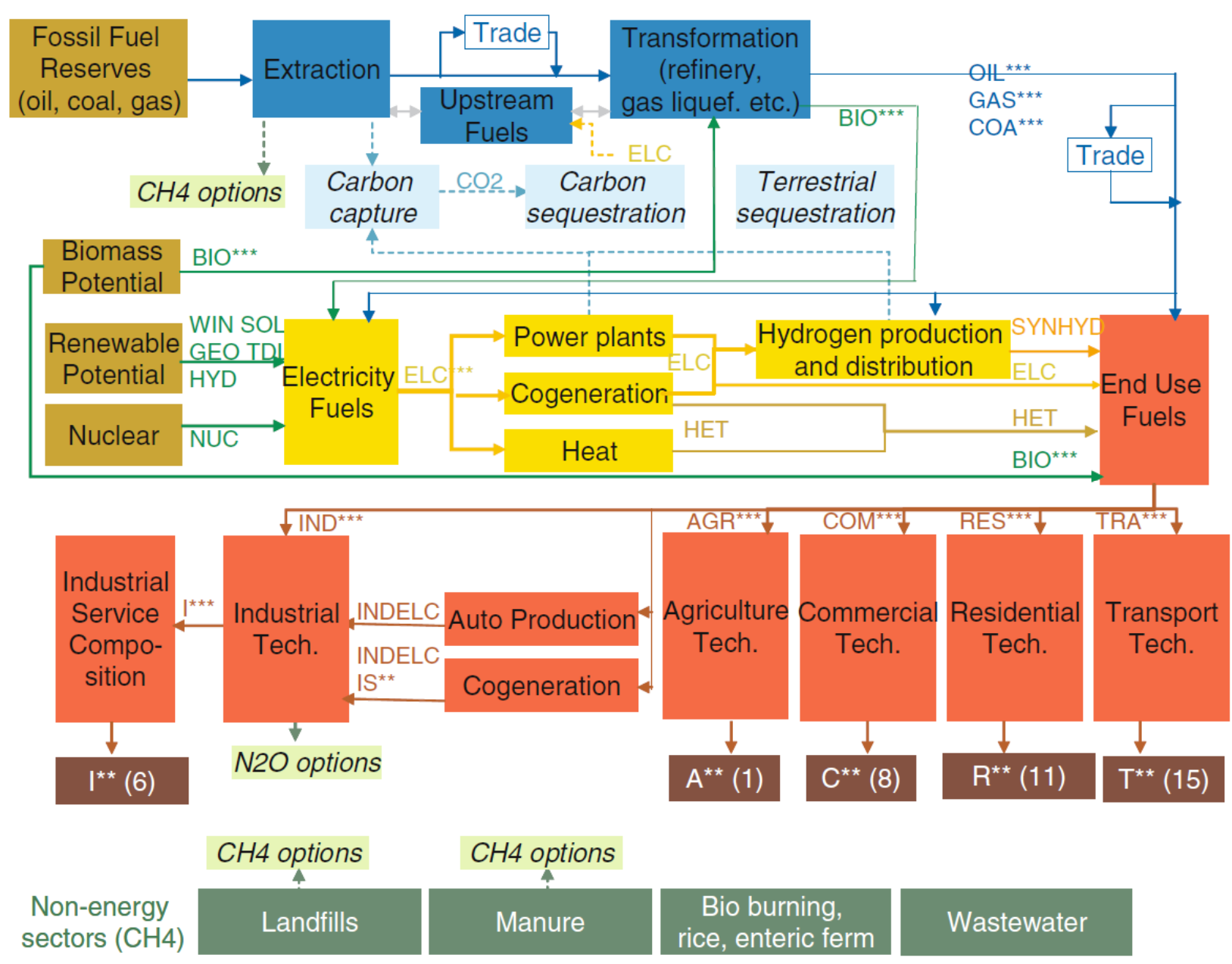

As seen above, all main sectors of the economy are represented in the TIAM-IFPEN: industry, residential, agriculture, commercial, transport and electricity generation. It computes a partial equilibrium which means that the suppliers of energy produce the quantity to meet

\footnotetext{
${ }^{6}$ Energy Technology Systems Analysis Program.

Created in 1976, it is one of the longest running Technology Collaboration Programme of the International Energy Agency (IEA). https://iea-etsap.org/

${ }^{7}$ Energy Flow Optimization Model
} 
the exogenous demand services considered. This equilibrium feature is present at every stage of the energy system. While computing the equilibrium, a TIAM run configures the energy system over a certain time horizon, in such a way as to minimize the objective function of the system, while satisfying a number of constraints. This objective function represents the total discounted cost of the system over the selected planning horizon. The model minimises the total discounted energy system cost in the standard version and maximises social welfare (consumer surplus + producer surplus) in the elastic demand version. All components of the system cost are specified yearly in the study horizon in contrary to the constraints and variables which are related to period for a better representation of the payment flows. The main cost components included in the objective function are the investment costs, fixed and variable operation and maintenance (O\&M) costs. Other cost components such as costs incurred for exogenous imports, revenues from exogenous exports, taxes and subsidies associated with commodity flows and process activities or investments are also included. All costs are discounting to the base year 2005 which is the reference year at which our TIAMIFPEN is calibrated. A complete description of the TIMES equations appears in ETSAP documentation [54].

As a technology explicit model, TIAM is based on a Reference Energy System which is a network of processes linked by their inputs and outputs, going from the energy supply sector to the energy consumption sector, through energy trade, transformation and conversion (Fig. 2). The existing and future technologies in the sectors over a given time horizon are considered with techno-economic parameters (capacity, energy intensity, conversion efficiencies, availability factor, investment costs, fixed and variable costs, future cost changes, maximum penetration rates, economic and technical life, etc.) and their related strategic orientation parameters (taxes, subsidies, etc.).

As reminded in all ETSAP documentation, solving the model means finding for each time period the optimum Reference Energy System by selecting the set of technologies and feedstock that provides the optimal energy-technology pathways. Thus, the model determines the optimal mix of technologies (capacity and activity) and feedstock at each period, the associated emissions, the mining and trading activities, the quantity and prices of all commodities, the equilibrium level of the demand for energy services, all in times series from the base year 2005 to the time horizon 2050 of the model.

Various studies have been already conducted with the TIAM model to analyse different climate change mitigation policies by the international modelling community - such as the role of nuclear energy [61], [62], the potential of shale gas development [63] or carbon capture and storage [64] in power supply in long-term climate scenarios. Some other recent studies have focused on the long-term decarbonisation of the global transport sector with 
electricity and hydrogen using TIAM-ECN ${ }^{8}$ [65] or TIAM-UCL ${ }^{9}$ [66]. Currently, to the best of our knowledge raw material LCIs have not yet been incorporated in a TIAM model.

\subsection{Details of modelling approach and scenarios}

\subsubsection{Data}

TIAM model is data driven, its parameterisation refers to technology characteristics, resource data, projections of energy service demands, policy measures etc. It means that the model varies according to the data inputs while providing results such as the shape of investments, technology pathways or the evolution of trade flows for policy recommendations.

Table 1 : Regions of the TIAM-IFPEN model

\begin{tabular}{|c|c|}
\hline TIAM name & Region \\
\hline AFR & Africa \\
\hline AUS & Canada \\
\hline CAN & China \\
\hline CHI & Central and South America \\
\hline CSA & India \\
\hline IND & Japan \\
\hline JAP & Middle-east \\
\hline MEA & Mexico \\
\hline MEX & Other Developing Asia \\
\hline ODA & South Korea \\
\hline SKO & United States of America \\
\hline USA & Europe 28+ \\
\hline EUR & Russia \\
\hline RUS & Central Asia and Caucase (Armenia, Azerbaijan, Georgia, \\
\hline CAC & Kazakhstan, Kyrgyzstan, Tajikistan, Turkmenistan, Uzbekistan) \\
\hline OEE & Other East Europe (Albania, Belarus, Bosnia-Herzegovina, \\
& Macedonia, Montenegro, Serbia, Ukraine, Moldova) \\
\hline & \\
\hline &
\end{tabular}

The model is disaggregated into 16 regions (Table 1). Each region has its own energy system with its main demand sectors. Each region can trade fossil resources, biomass, materials or emission permits with other regions or in a centralized market. Thus, the model fully describes within each region all existing and future technologies from supply (primary resources) through the different conversion steps up to end-use demands.

The following power generation technologies have been covered by the model: renewable energy technologies (RETs) (solar PV and CSP, wind onshore and offshore, hydro, biomass), fossil-based technologies (coal, natural gas, oil) and nuclear. Most techno-economic

\footnotetext{
${ }^{8}$ TIAM-ECN is a version of TIAM adapted at the Energy research Centre of the Netherlands (ECN)

${ }^{9}$ TIAM-UCL is a version of TIAM developed at UCL (University College of London) through the UK Energy Research Centre (UKERC) by breaking out the UK from the Western Europe.
} 
parameters (capacity, energy intensity, efficiency, availability factor, investment costs, fixed and variable costs, economic and technical life, etc.) and the inventories of the existing and future generation technologies were taken from the World Energy Outlook 2016 [67], IRENA [68] and the European Commission database. An evolution of regional investment costs of the main technologies has been displayed in Fig. 3 and Fig. 4. The investment cost of a technology in Europe region in 2010 is considered as the reference index for regional comparison. We assumed a continuing decrease of the RETs costs over the studied period till 2050 in line with IRENA and IEA. Fig. 3 : Average renewable energy technology (RET) investment costs at regional level
between 2010-2050 (Index CostEUR (2010 $_{20}=1$, red line)

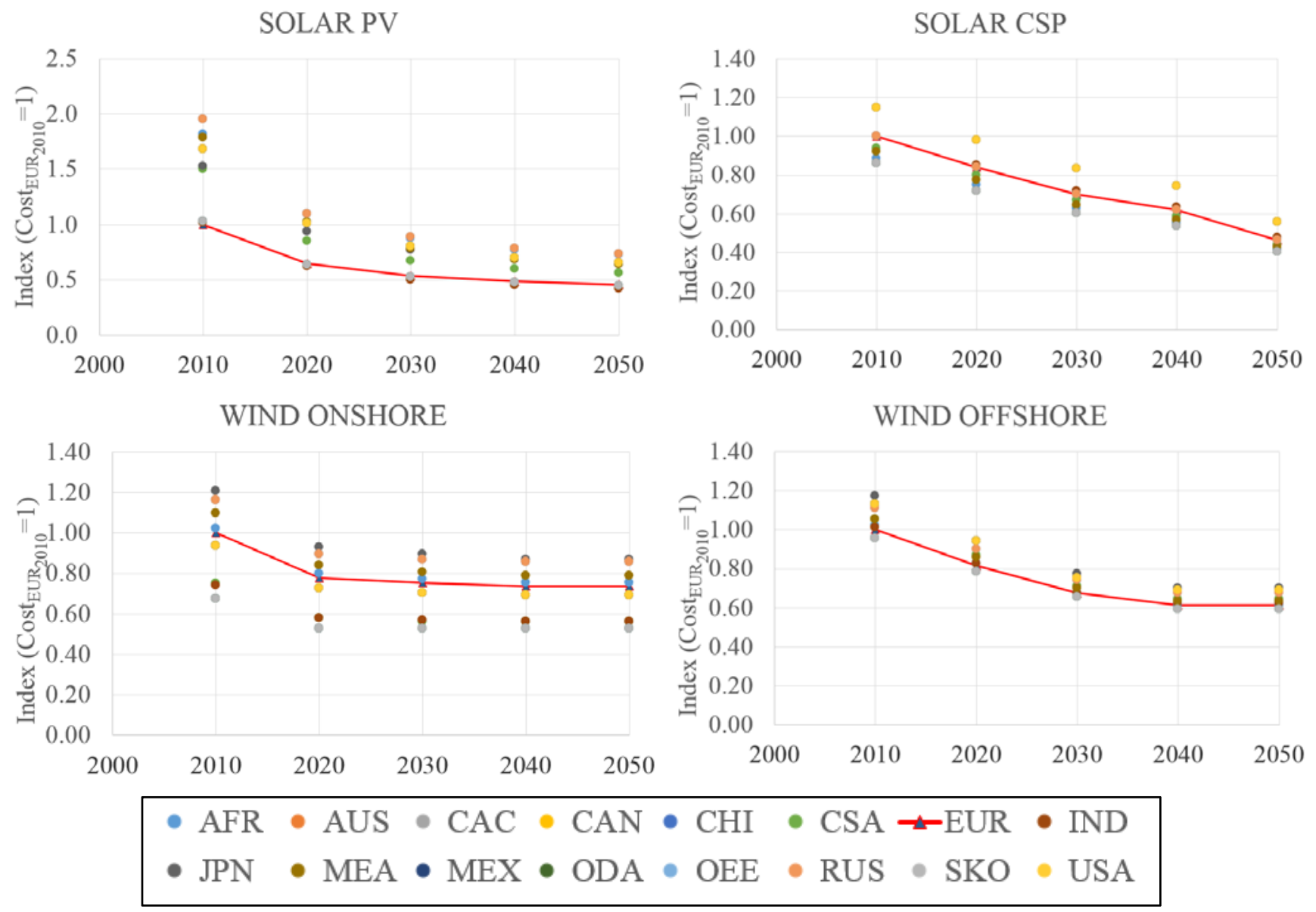

On the contrary, the regionalized fossil-based power plants costs remain constant over the same period. As with any model, the results of TIAM-IFPEN scenario runs are sensitive to the input parameters values. 
Fig. 4 : Average technology investment costs at regional level between 2010-2050 (Index CostEUR $2010=1$, red line)

NUCLEAR

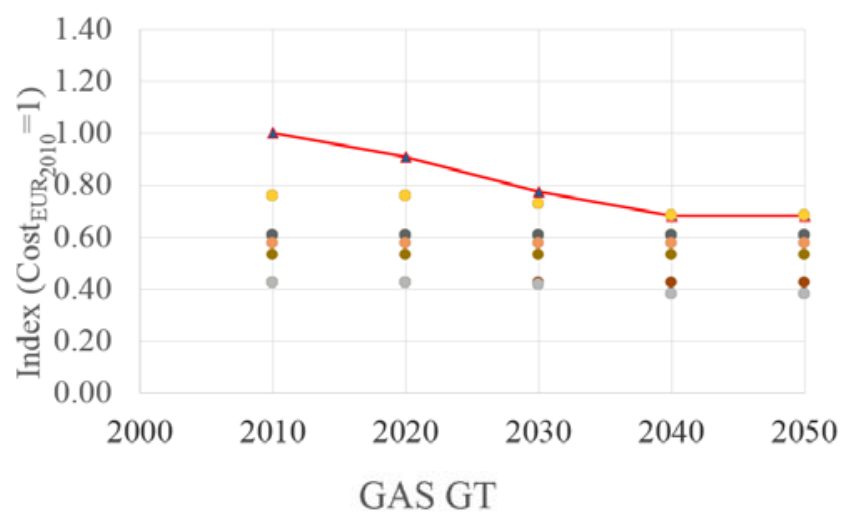

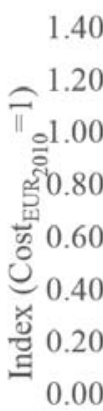

GAS GT

$\begin{array}{llllll}2000 & 2010 & 2020 & 2030 & 2040 & 2050\end{array}$
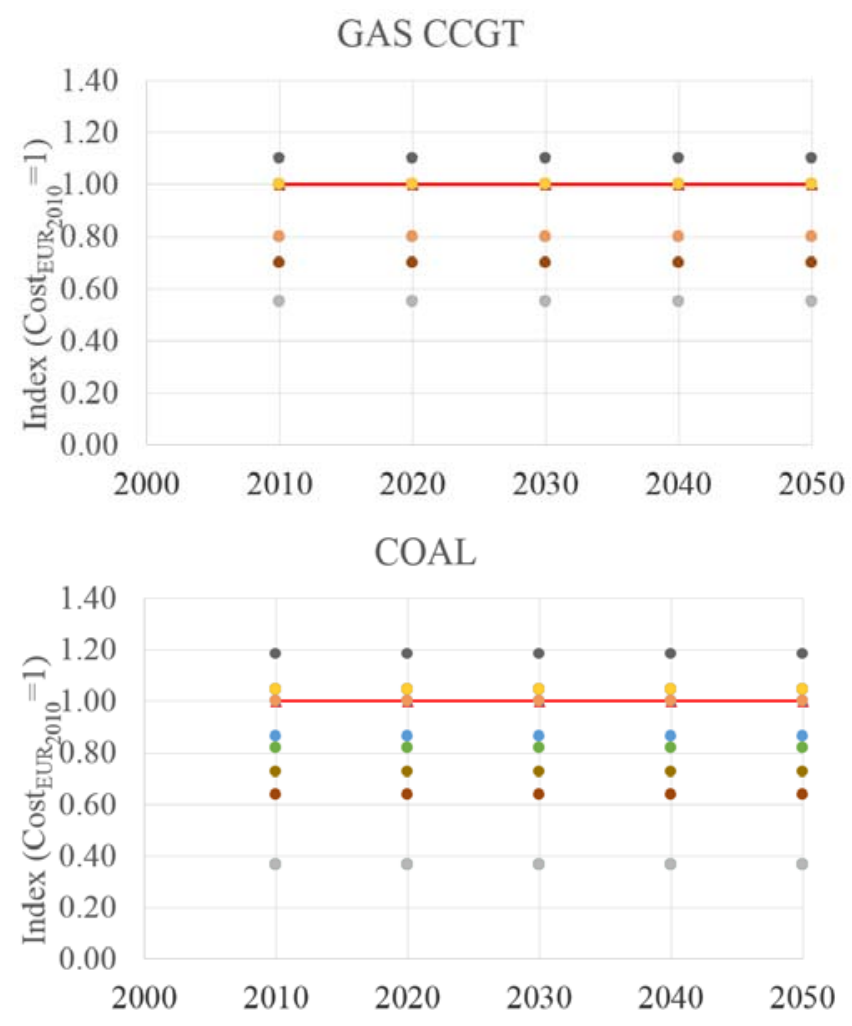

$$
\begin{aligned}
& \bullet \mathrm{AFR} \bullet \mathrm{AUS} \bullet \mathrm{CAC} \bullet \mathrm{CAN} \bullet \mathrm{CHI} \bullet \mathrm{CSA} \pm \mathrm{EUR} \bullet \mathrm{IND} \\
& \bullet \mathrm{JPN} \bullet \mathrm{MEA} \bullet \mathrm{MEX} \bullet \mathrm{ODA} \bullet \mathrm{OEE} \bullet \mathrm{RUS} \bullet \mathrm{SKO} \bullet \mathrm{USA}
\end{aligned}
$$

CCGT: Combined Cycle Gas Turbine, GT: Gas Turbine

As perfectly reminded by Schimpf et al. [69], it is important to understand that a scenario is neither a mere forecast - in the sense of an unsurprising projection of the present - nor is it expressing a vision, i.e. a desired future. Therefore our results should not be considered as forecasts but rather as projections of the possible pathways of a future energy system development. All energy demand projections have been done considering macro-economic drivers such as the GDP, the population growth, etc. (Statistics/outlook of the $\mathrm{IMF}^{10}$, results from GEMINI-E3 or GEM-E3 macro-economic models). All assumptions related to regional fossil fuel reserves and trade capacities have also been implemented along with the regional renewable energy potentials ([70], World Energy Council, BP Statistics, US Geological Survey, specialized literature and experts involved in the projects). For the power generation, the general sources of data are the National Renewable Energy Laboratory (NREL), PLATTS database, IRENA, WEO IEA and specialized literature.

\footnotetext{
${ }^{10}$ International Monetary Fund
} 


\subsubsection{Overview of the lithium supply chain}

The lithium supply chain has been built from ore deposits to its end-use via various transformation processes and trade flows (Fig. 5). Two types of trade are included in the model: the first one is about lithium ore from the mineral deposits to the refining sites. As of today, the main flow is from Australia to China. The second type concerns the main lithiumbased chemicals $\left(\mathrm{LiOH}\right.$ and $\left.\mathrm{Li}_{2} \mathrm{CO}_{3}\right)$. Both products are aggregated in the same trade flows as they are not differentiated according to their specific end-use. Taking into account the trade capabilities will allow analysing future international lithium exchanges according to the each regional needs and growth.

\section{Fig. 5 : Detailed description of lithium in each TIAM region}

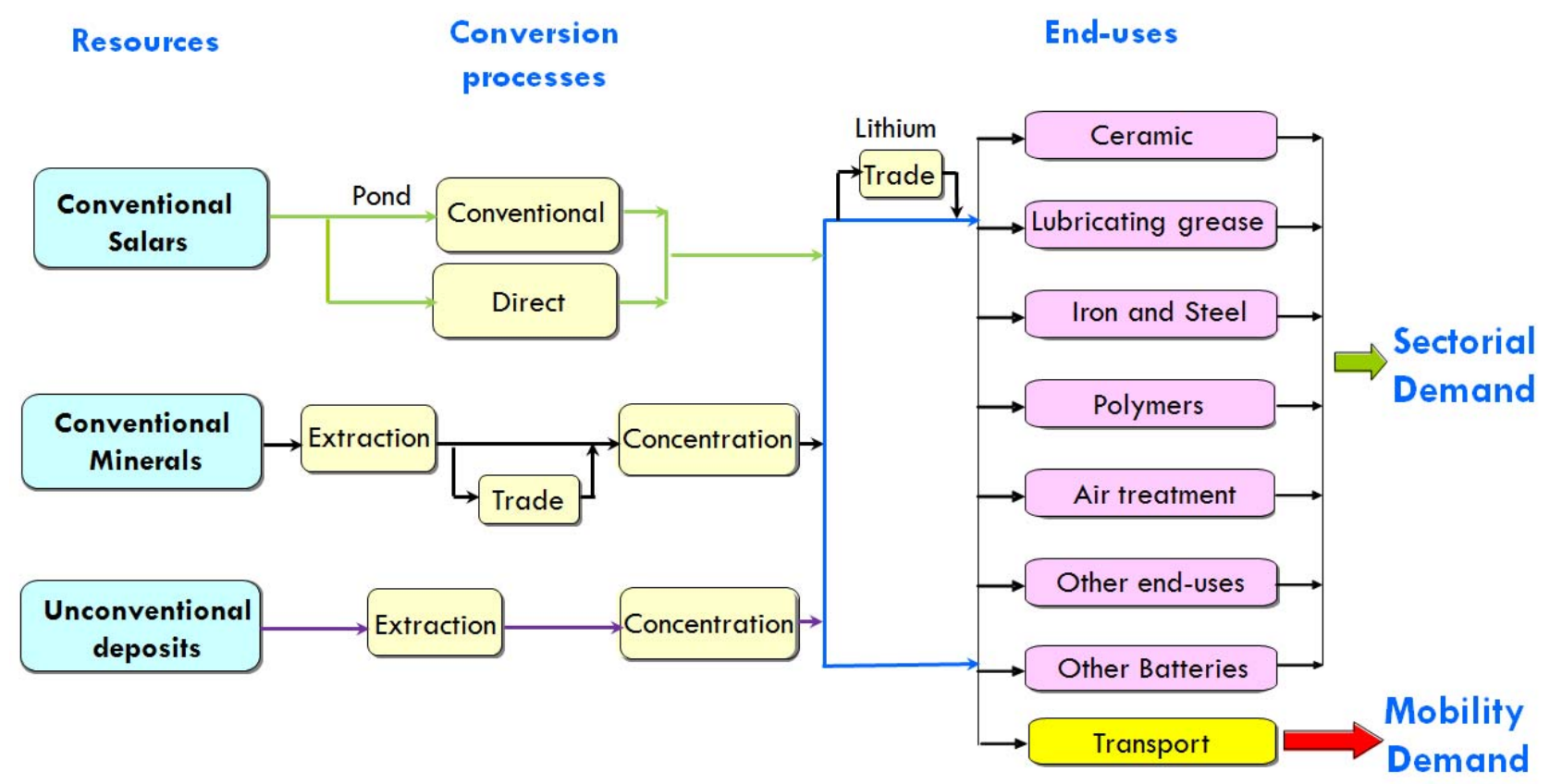


Fig. 6 : Distribution of resources (dotted line) and primary production (solid line) worldwide, with the main companies operating at current production sites and ongoing projects (Data 2017)

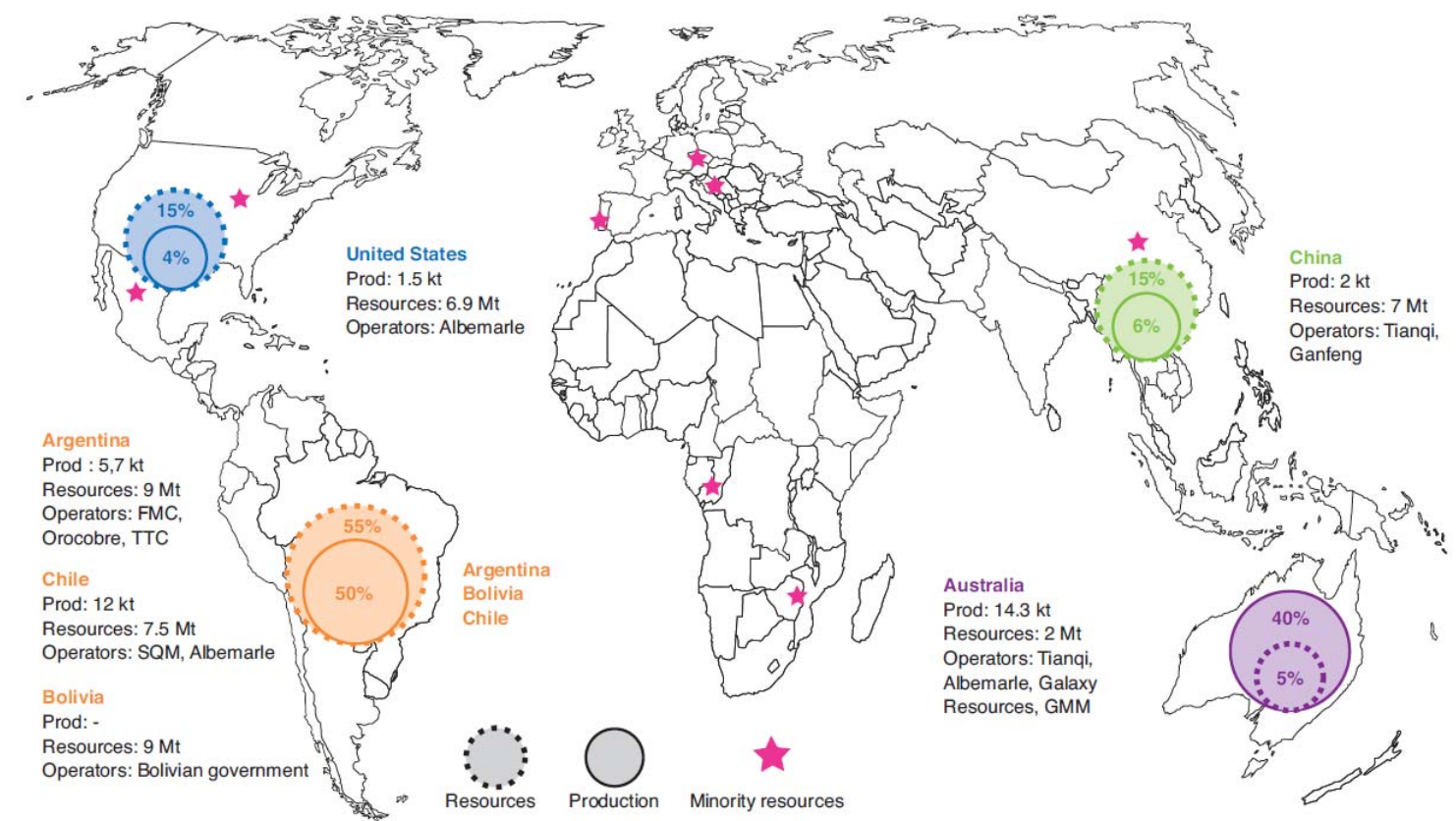

Source: USGS (2017), producer announcements

Table 2 : Regional disaggregation of the lithium resources (in Mt) by type of deposits

\begin{tabular}{|c|c|c|c|c|c|c|c|c|c|c|c|c|c|c|c|c|}
\hline & AFR & AUS & CAC & CAN & $\mathrm{CHI}$ & $\mathrm{CSA}$ & EUR & IND & JPN & MEA & MEX & ODA & OEE & RUS & SKO & USA \\
\hline Brine & & & & & 5.25 & 25.5 & & & & & & & & & & 2.07 \\
\hline Mineral & 1.2 & 2 & & 2 & 1.75 & 0.2 & 0.01 & & & 1.5 & & & & 1 & & 4.14 \\
\hline Clay & & & & & & & 1.033 & & & & 0.845 & & 1.033 & & & 0.69 \\
\hline
\end{tabular}

Source: USGS 2017

Fig. 7 : The various lithium deposits

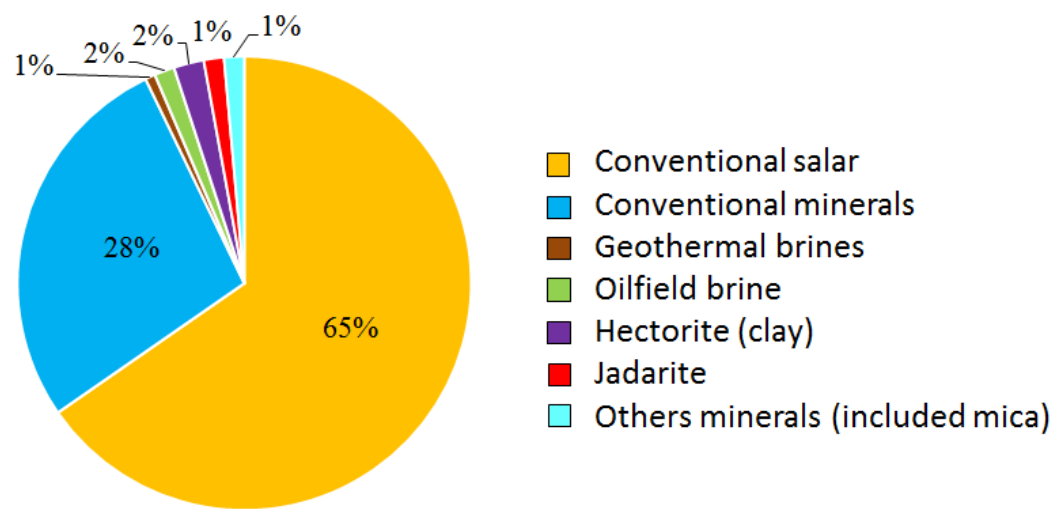

Source: USGS 2017

Three different deposits have been considered (Table 2) in the model: two conventional deposits (brine from salars and minerals ${ }^{11}$ ) and an unconventional lithium one (Fig. 7$)^{12}$

\footnotetext{
${ }^{11}$ Lithium-bearing rock (specifically spodumene).

${ }^{12}$ Several unconventional lithium deposits have been identified including hectorite (clay), jadarite, geothermal brine, oilfield brine, and even ocean brine.
} 
according to their regional reserves and resources. The associated technology is then described and differentiated by region in terms of investment, operations and maintenance costs, capacity of production and efficiency. Note that at present, less than $1 \%$ of lithium is recycled. If lithium recovery from Li-ion batteries is technically feasible with high recovery rate (about $80 \%$ at the laboratory scale) it seems that lithium recycling would be far from widespread. Considering the low percentage by mass (about 3\%) and the current lithium price, strong political incentives are needed for widely deploying this sector. For instance, based on the 2006/66/EC European directive, where the minimum recycling efficiency of NMC batteries is $50 \%$ by average weight, there is little incentive to recover lithium compared with cobalt for example. The latter is much more profitable because lithium recycling requires the use of highly-complex processes, which are not currently economically viable [71]. Even though batteries are partly recycled to recover higher-value metals such as cobalt, there is currently no specific recycling system for lithium. However, Li et al. [72] have studied the cost-effective supply chain for electric vehicle battery remanufacturing using an optimization model. They pointed out that almost $10 \%$ of profit could be achieved by integrating remanufacturing into Lithium-ion battery supply chain networks already implementing recycling through. Their results are promising and show the importance of "the processing costs, transportation cost, and how spent battery returns will dictate the profitability of the network". In the absence of a supply chain representation for electric vehicle lithium-ion battery and its remanufacturing in our TIAM model, errors can therefore be made. Moreover, the results of $\mathrm{Li}$ et al. are very sensitive to the parameters as specified by the authors and we cannot apply them to all regions of the model since this would imply that the best technologies have spread instantly. The importance of transport costs suggests that the viability of recycling exists when it is (relatively) local. Thus, we did not take into account the recycling parameter in the model.

\subsubsection{The transport sector in TIAM-IFPEN}

The transport sector has been divided into passenger light-duty vehicles (PLDV) (small, medium and large), bus, minibus, commercial vehicles (CV) (light, heavy and medium trucks) and 2/3-wheelers (Fig. 8). The presentation of technologies relies on a specific understanding of the transport sector within each segment (PLDV, CV, bus, minibus and 2/3-wheelers). 
Fig. 8 : Overview of the transport technologies considered in TIAM-IFPEN model
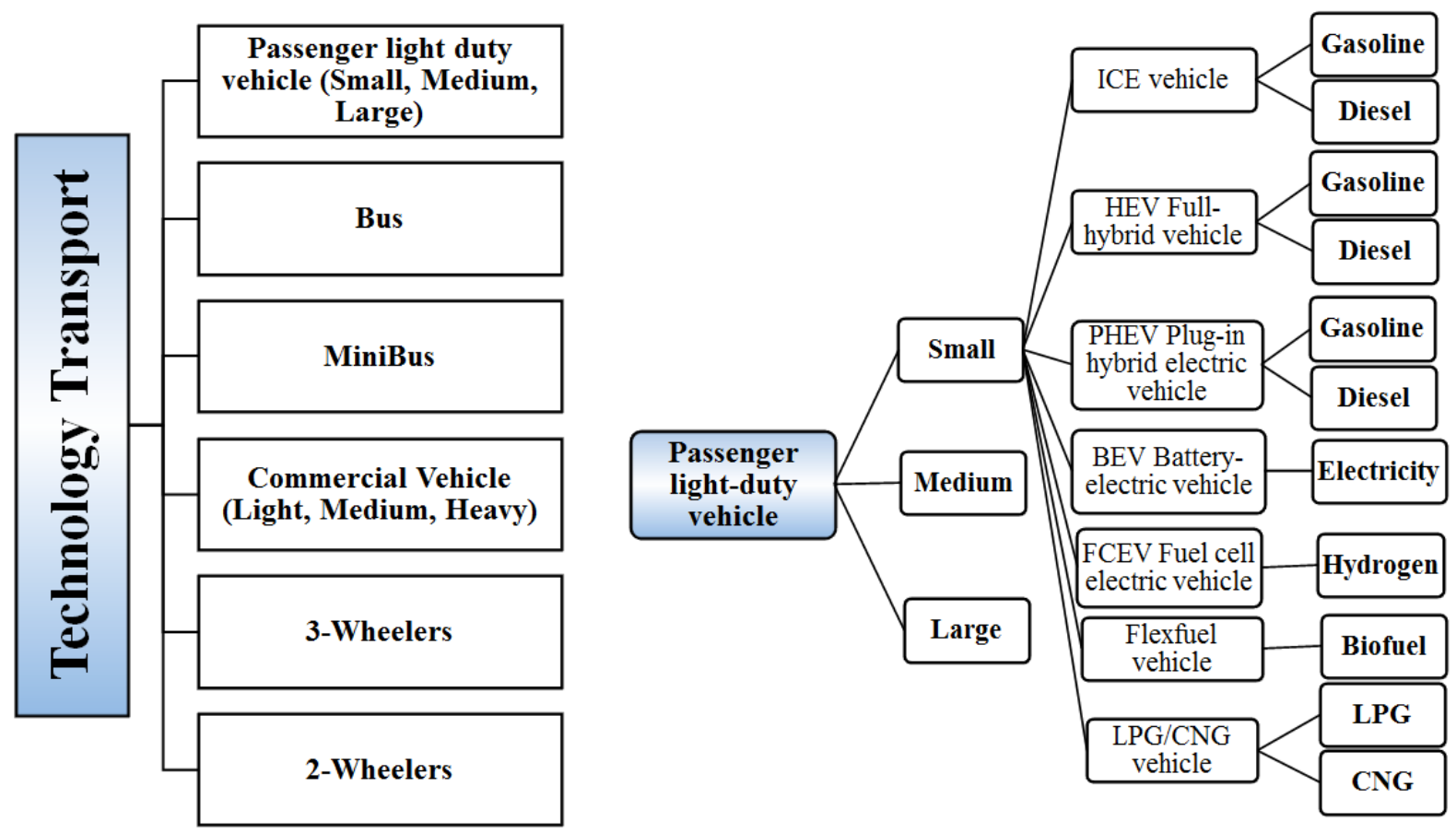

The existing and future vehicles have been implemented with their techno-economical parameters. For all technologies across entire study period 2005-2050, we took into account efficiency (fuel consumption in short and long distance), average annual vehicle mileage, lifespan, cost (purchase cost, O\&M fixed and variable costs), etc. All these attributes have been derived from the IEA data on transport, and the BEAVeR ${ }^{13}$ and FSIM $^{14}$ models developed by IFPEN.

Fig. 9 : Share of lithium consumption by various end-use sectors in 2017

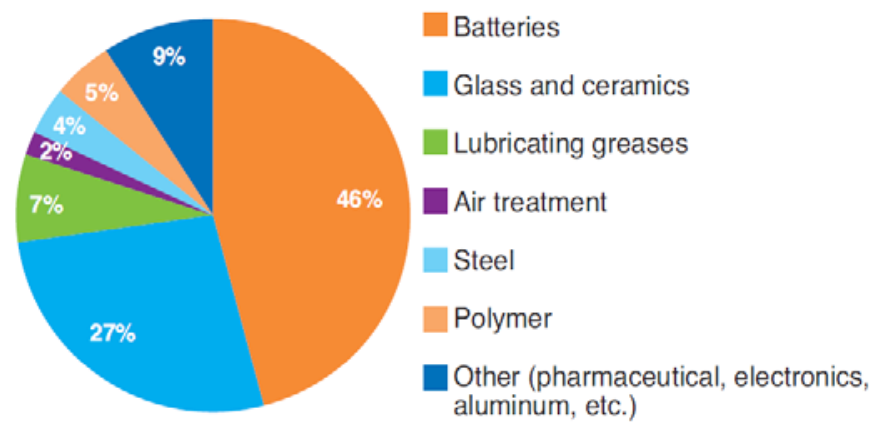

Source: USGS 2018

\footnotetext{
${ }^{13}$ BEAVeR (Economic and Life-Cycle Assessment of road vehicles) model is a TCO model which allows calculation and comparison of ownership and usage costs for various road vehicles, whether private vehicles, utility vehicles, buses or heavy trucks

${ }^{14}$ FSIM (Fleet SIMulator) model enables the study of dynamics in the private vehicle market, the impact of a wide range of instruments and public policies, and assesses the environmental impact of these policies. FSIM is based on individual behavior, in that it simulates changes in consumer behavior in response to changing economic conditions
} 
The battery sector is now the primary outlet, with one-third of this lithium end-use applied to electric vehicles (Fig. 9). In the transport sector, Li-ion based technology is considered for all the lifetime period. The lithium content is based on the NMC technology, disaggregated per vehicle size (Table 3) with an energy intensity per kWh increasing over the period.

Table 3: Lithium content considered in battery-powered electric vehicles (in kg per vehicle) for the year 2015 and 2030

\begin{tabular}{|c|c|c|c|c|c|c|c|c|c|}
\hline & $\begin{array}{c}\text { Small } \\
\text { car }\end{array}$ & $\begin{array}{c}\text { Medium } \\
\text { car }\end{array}$ & $\begin{array}{c}\text { Large } \\
\text { car }\end{array}$ & Bus & Minibus & $\begin{array}{c}\text { Light } \\
\text { CV }\end{array}$ & $\begin{array}{c}\text { Medium } \\
\text { CV }\end{array}$ & $\begin{array}{c}\text { Heavy } \\
\text { CV }\end{array}$ & $\begin{array}{c}\text { 2- } \\
\text { wheelers }\end{array}$ \\
\hline $\mathbf{2 0 1 5}$ & 8 & 12 & 17 & 68 & 34 & 16 & 34 & 51 & 1 \\
\hline $\mathbf{2 0 3 0}$ & 9 & 12 & 17 & 51 & 25.5 & 18 & 30 & 45 & 1.2 \\
\hline
\end{tabular}

CV: Commercial vehicle

A positive growth has been observed in recent years for all end-use sectors (except for the lubricants ), especially batteries, where lithium consumption is increasing by about $20 \%$ per year. Therefore, when considering future demand in lithium, all end-uses might be considered in the modelling exercise. Based on literature and producers' data, estimated growth rates have been considered from nowadays up to 2030 and beyond for all end-use sectors except for transport (Table 4). For all sectors (excluding transport), the evolution of their demand up to 2050 is exogenous inputs. For the case of the transport sector, the mobility demand of all transport vehicles has been implemented in the model. The latter will derive the evolution of the world fleet of vehicles which will satisfy this mobility demand. TIAM-IFPEN model will assess the level of lithium needed according to the new vehicles available at any period. Under these assumptions, the model is then able to account for the structural effect into the lithium demand evolution.

Table 4: Lithium consumption growth annual rates according to the existing end-uses

\begin{tabular}{|c|c|c|}
\hline End-sector use & \multicolumn{2}{|c|}{ Annual growth rates } \\
\hline & Now to $\mathbf{2 0 3 0}$ & $\begin{array}{c}\mathbf{2 0 3 0} \\
\mathbf{2 0 5 0}\end{array}$ \\
\hline Batteries (excluding transport) & $8 \%$ & $2,5 \%$ \\
\hline Glass and ceramics & $5 \%$ & $2 \%$ \\
\hline Lubricating greases & $3 \%$ & $2 \%$ \\
\hline Iron and steel & $5 \%$ & $1 \%$ \\
\hline Polymers & $3 \%$ & $0 \%$ \\
\hline Air treatment & $2 \%$ & $2 \%$ \\
\hline $\begin{array}{c}\text { Other (pharmaceutical, electronics, aluminium, } \\
\text { etc.) }\end{array}$ & $5 \%$ & $4 \%$ \\
\hline
\end{tabular}

Sources : [41], Dakota Minerals, USGS, auteurs (2017) 


\subsubsection{Scenario specification}

Our scenarios have been defined to observe the evolution of the transportation sector in response to environmental constraints at global level, lithium resource availabilities and the implications of future mainstream in road passenger transport mobility. The demand for travel and motorization has increased dramatically over the past few decades along with economic development and population growth [73]. In recent years, a change of individual travel behaviour in road passenger transport has been observed due to the promotion of the use of alternative forms of transport (walking, cycling, shared mobility and public transport). As acknowledged by the UN-Habitat, while the global trends of the implications of the unfolding events of rapid urbanization, hyper-mobility and the health and climate hazards associated with car-dependencies pose uncertainties and risks, there are also unprecedented opportunities for advancing sustainable urban mobility [74]. Many governments around the world have been constantly adjusting its transport policies overtime through an integrated approach to land use and transport planning, transport pricing (congestion pricing schemes, road tolls), parking restrictions to challenge car attractiveness while providing alternative modes of transport ${ }^{15}$ [75], [76]. Therefore, for the purpose of the present study, we run four scenarios where we have considered two climate scenarios ${ }^{16}$ with two different shapes of mobility each in order to assess the impact on the lithium market along with the transportation electrification:

- Scen 4D which is consistent with limiting the expected global average temperature increase to $4^{\circ} \mathrm{C}$ above pre-industrial levels by 2100 .

- Scen 2D which is a more ambitious scenario, which translates the climate objectives of limiting global warming to $2^{\circ} \mathrm{C}$ by 2100 .

In each climate scenario, different future shapes of mobility have been assumed and derived from the IEA Mobility Model (MoMo Model). The MoMo model is a technical-economic database spreadsheet and simulation model that enables detailed projections of transport activity according to user-defined policy scenarios to 2060. The model covers 29 countries and regions including a urban/non-urban split, and the potential for municipal-level policies to reduce transport energy use. As explained by the IEA, "the MoMo model includes key elasticities, based upon representative "consensus" literature values, are used to model vehicle activity and fuel consumption responses to changes in fuel prices - which are themselves driven by projections and policy scenarios (i.e. GHG or fuel taxes). Elasticities also enable

\footnotetext{
${ }^{15}$ Cycle lanes, pedestrian areas and public transport coverage have been expanded while new mobility options such as bike- and car-sharing schemes have been introduced, underpinned by the development of the ICT (information and communication technology).

${ }^{16}$ The climate module per se is directly inspired by Nordhaus-Noyer model.
} 
vehicle ownership to vary according to fuel prices and income, as proxied by GDP per capita". Thus, they derived two future shape of mobility which would take into account the evolution of the ownership rates (number of vehicles per inhabitants), evolution of city density (density of cities with potential access public transport) according to their size. The research strategy of the MoMo project is detailed on the Fig. 10

\section{Fig. 10 : The network of spreadsheets of the IEA Mobility Model (MoMo model)}

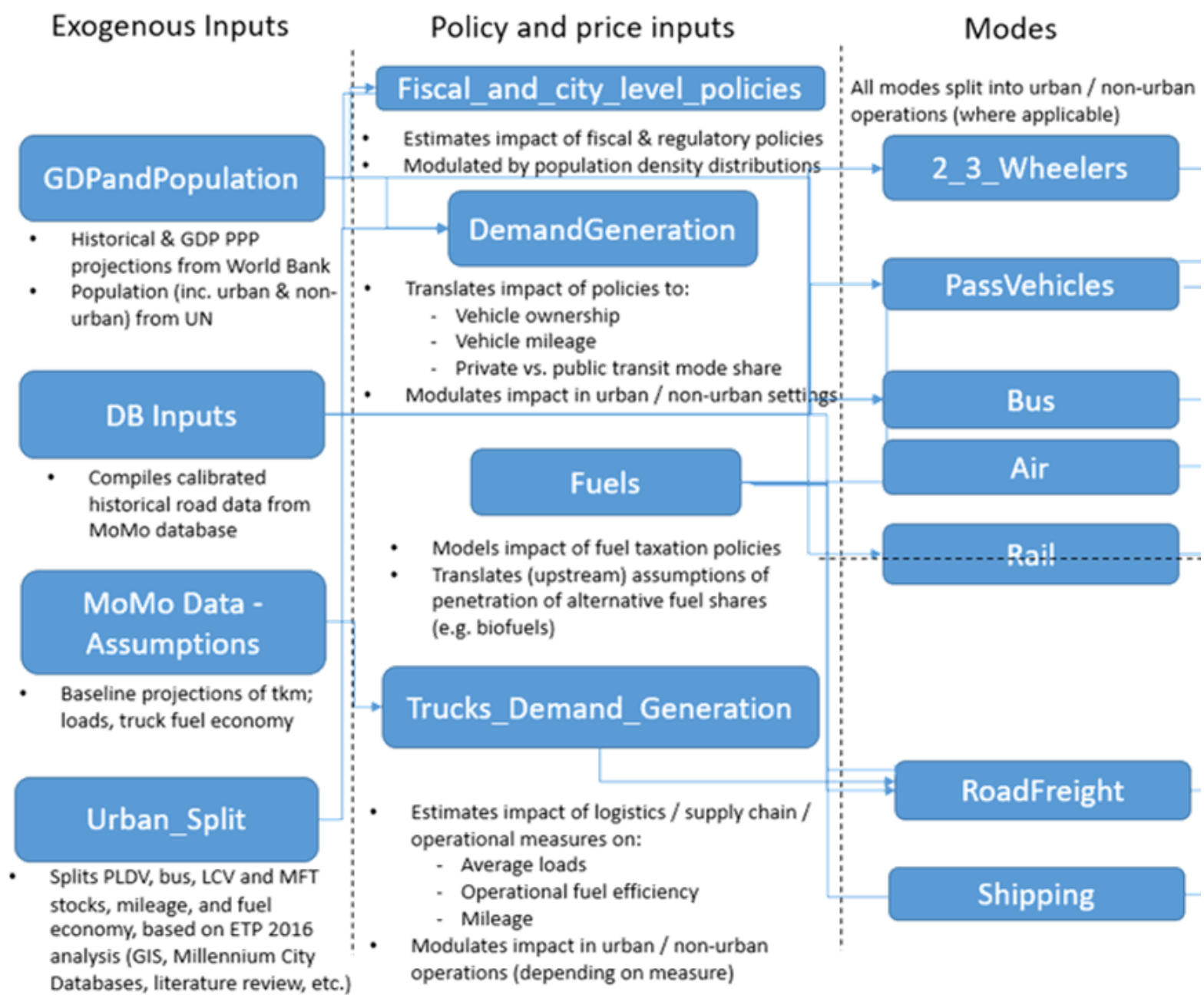

Source: IEA Mobility model

In this paper, we incorporate the outputs of the MoMo model as inputs of transport mobility in our TIAM-IFPEN, there are two mobility scenarios for each climate scenario (Fig. 11):

- A High mobility shape equivalent to a continuing increase of the ownership rate, more private transit mode share and lower city densities. It is assumed an impact of urban dispersal, a worldwide phenomenon, on mobility and travel as well as the influence of urban land coverage on travel where we keep on having a huge car dependency and usage. As acknowledged by the UN, urban dispersal has an unmistakable and profound influence on travel because of the fact that spread-out growth increases the 
use of private motorized vehicles. Nowadays, this "urban sprawl"17 is increasingly widespread in developing countries and should be considered in transport modelling.

- Hypothesis of a Low mobility shape where the idea of a sustainable mobility is assumed. This assumption implies more impact of stronger fiscal and regulatory policies, less vehicle mileage with more compact cities. It underpins an integrated approach to urban land-use and transport planning and investment, and gives priority to sustainable modes of mobility such as public and non-motorized transport as seen in Fig. 11 with the bus and minibus travel demands.

Fig. 11 : Evolution of the two different shape of mobility (high and low) according to the travel mode (short and long distance)

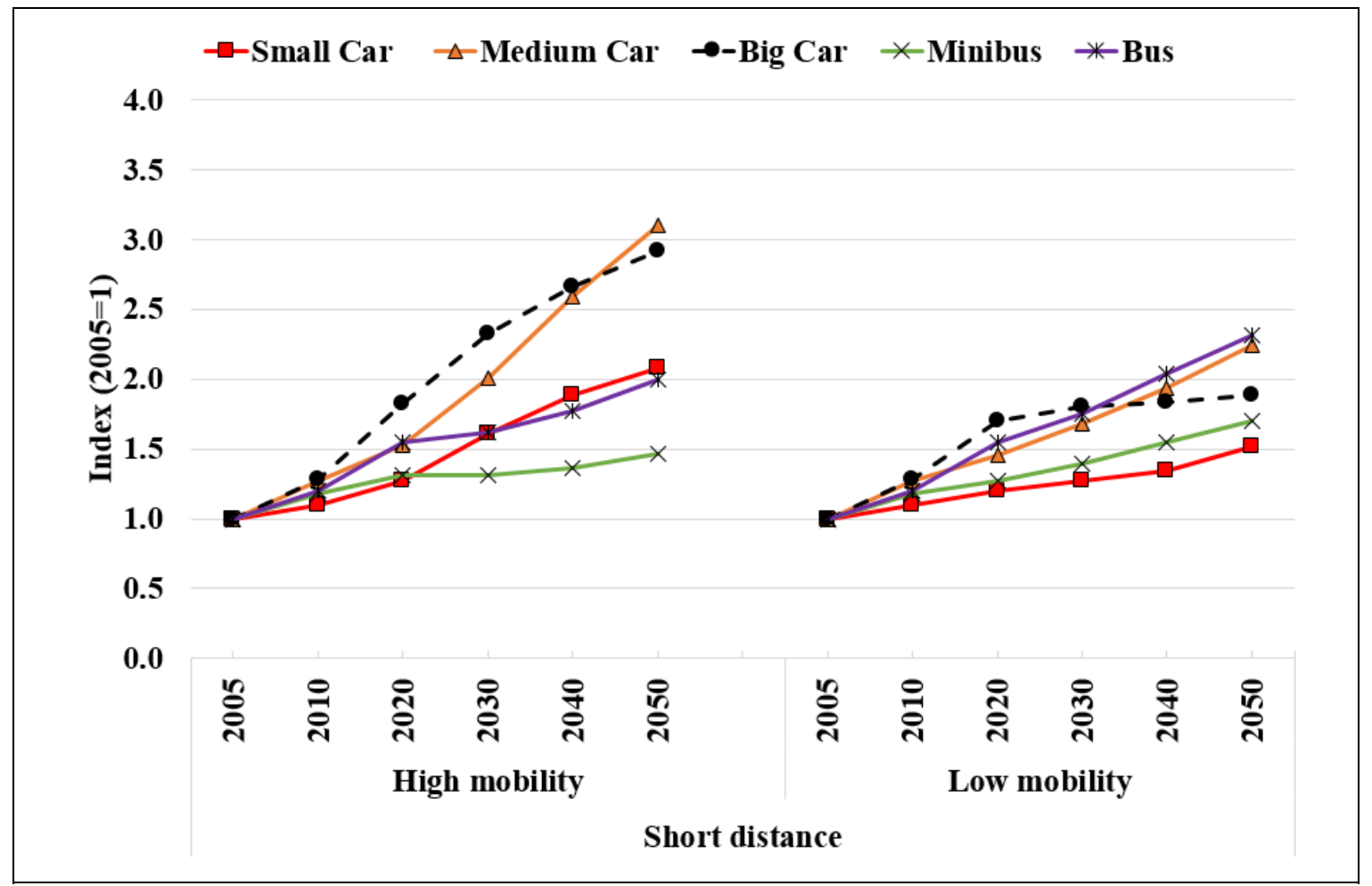

17 The term "urban sprawl" describes low-density, dispersed, single-use, car-dependent built environments and settlement patterns that, critics charge, waste energy, land and other resources and divide people by race, ethnicity and income/wealth [74]. 


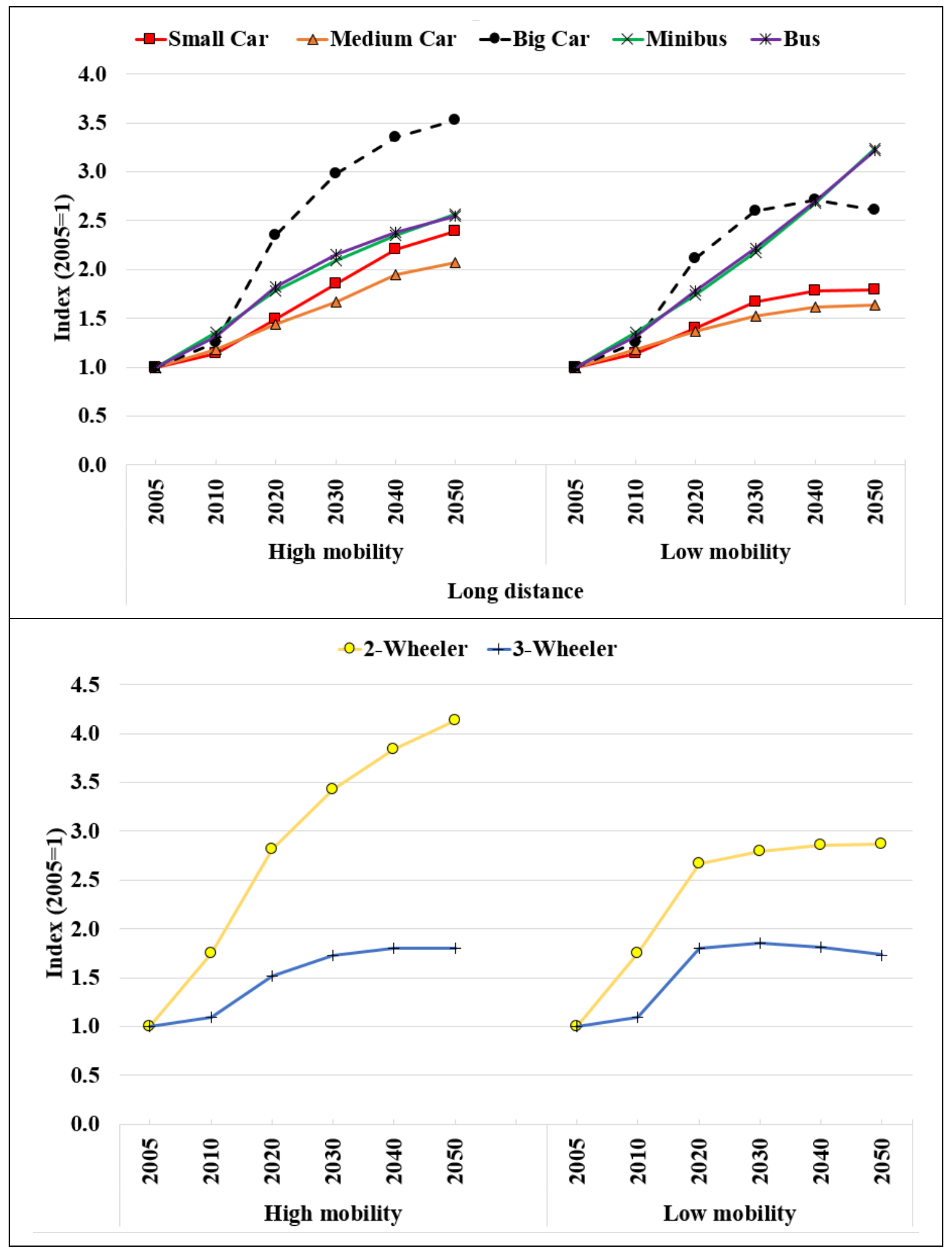

Source: IEA Mobility model

As seen in Fig. 11, the travel demand has been also disaggregated into two types of vehicle usages: short distance (urban) and long distance (extra-urban) for all vehicles except for the heavy commercial vehicle (HCV) and the 2/3-wheelers. This paper aim to contribute to the transport policy literature by modeling the implications of different shape of mobility along 
with climate constraints, firstly on cars fleet evolution and secondly on the regional lithium needs in regards to the resource availability in the future.

\section{Results and discussions}

\subsection{World transportation fleet}

Fig. 12 presents the changes in the global vehicle stock (including 2/3-wheelers) by powertrain for all scenarios. With a sustainable mobility, the worldwide fleet achieves 2.3 and 2.1 billion vehicles respectively in the $4^{\circ} \mathrm{C}$ and the $2^{\circ} \mathrm{C}$ scenarios by 2050 . Meanwhile, it is more than 3.3 billion and around 3 billion respectively in $4^{\circ} \mathrm{C}$ and $2^{\circ} \mathrm{C}$ scenarios with a hypermobility. A reduction in the global fleet is also observed when the climate constraints are more stringent for a same mobility

There is a preponderance of internal combustion engine (ICE) vehicles (more than half of the global fleet) in the scenario $4^{\circ} \mathrm{C}$ both in high and low mobility with gradual penetration of electric vehicles (EVs). Meanwhile, in the $2{ }^{\circ} \mathrm{C}$ scenario, they decrease to around $20 \%$ and $15 \%$ of the global fleet respectively under an hypothesis of low mobility and high mobility. Electric vehicles will increase steeply over the time horizon in both climate scenarios by 2050: between $30 \%$ and $22 \%$ of the global fleet in the $4^{\circ} \mathrm{C}$ scenario respectively in low and high mobility, while around $75 \%$ in the $2^{\circ} \mathrm{C}$ scenario in both mobility hypothesis.

Fig. 12 : Evolution of the global vehicle stock between 2005-2050

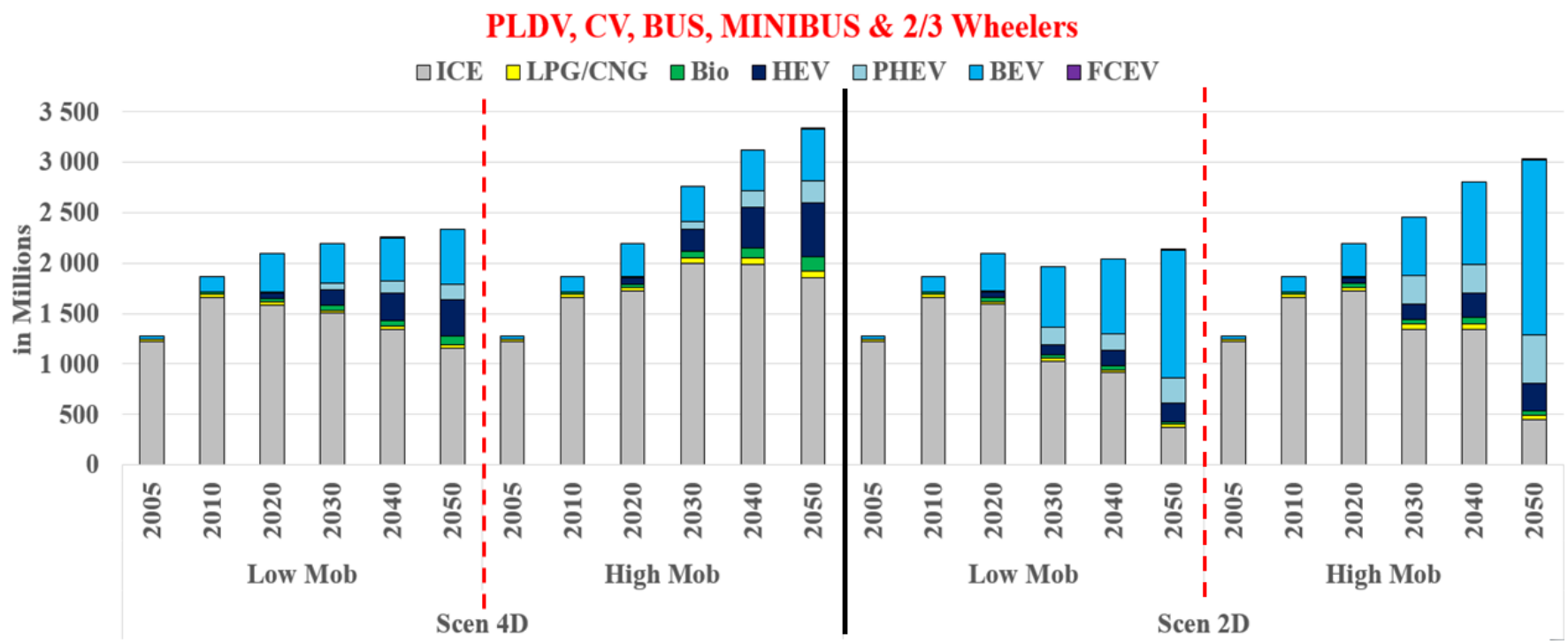

ICE: Internal combustion engine; HEV: Full hybrid vehicle; PHEV: Plug-in hybrid vehicle; BEV: Battery-powered electric vehicle; FCEV: Fuel cell electric vehicle 
It should be highlighted that the EV fleet is mostly located in Asian countries (China, India and other developing countries in Asia) due to the large presence of two and three-wheelers that stand for more than half of the global EV fleet.

\section{Fig. 13 : Evolution of the global EV stock (two and three-wheelers excluded) between} 2005-2050. (a) $4^{\circ} \mathrm{C}$ scenario (b) $2^{\circ} \mathrm{C}$ scenario

(a)

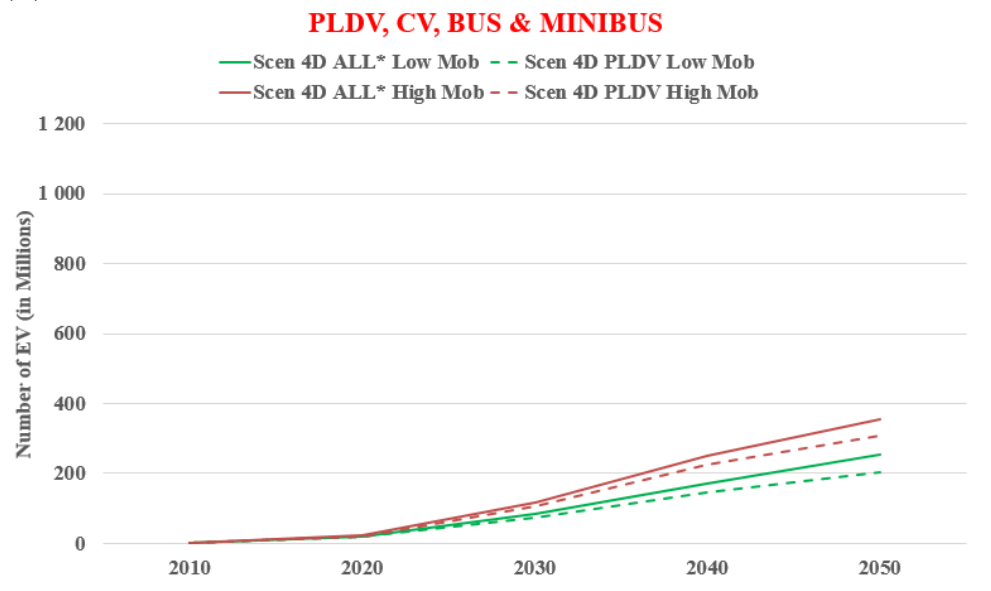

(b)

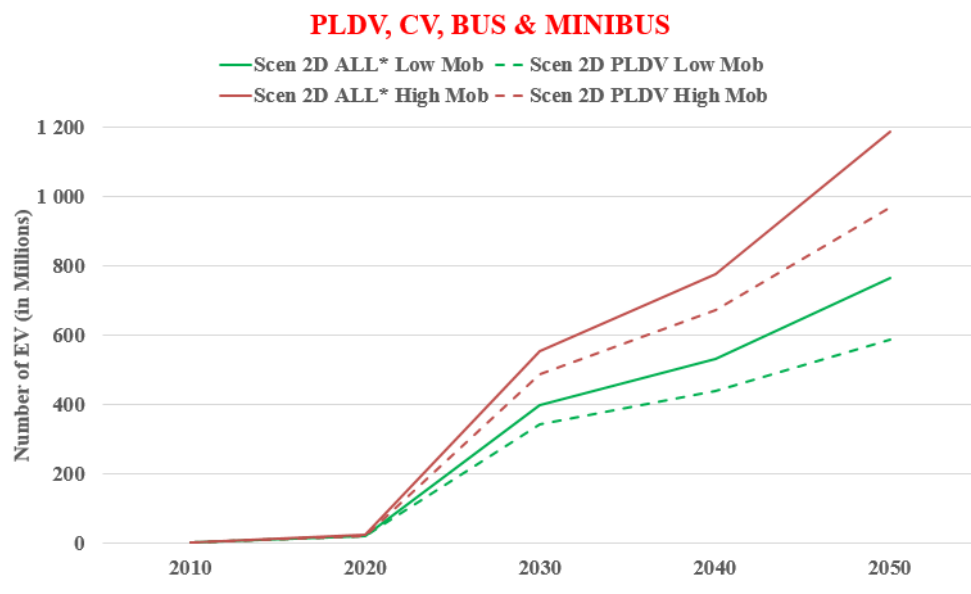

PLDV: Passenger Light-duty vehicle; CV: Commercial vehicle

According to Fig. 13 (a) and (b) (solid lines), the global fleet of EV (two and three-wheelers excluded) should reach between 250 and 360 million units by 2050 in the $4^{\circ} \mathrm{C}$ scenarios, while it could be as high as 760-1200 million units in the $2^{\circ}$ scenarios. When considering passenger light-duty vehicles (PLDVs: small, medium and large cars) alone, they should reach 205 and 310 million units in circulation by 2050 in the $4^{\circ} \mathrm{C}$ scenarios respectively with the low and high mobility hypotheses (Fig. 13 (a) dotted lines). On the other hand in Fig. 13 (b) (dotted lines), it would be around 590 and 970 million units respectively in the low mobility and high mobility assumptions of the $2{ }^{\circ} \mathrm{C}$ scenario.

Analysing these graphs, we could acknowledge that our forecasts in the $4^{\circ} \mathrm{C}$ scenario with no change of individual travel behaviour in road passenger transport (high mobility), 115 million units by 2030, are similar in scope to the IEA's forecasts in the Global EV Outlook 2018 [59], which estimates the number of EV at between 130 and 230 million by 2030 . 
Fig. 14 : Evolution of the global EV stock by vehicle's category between 2005-2050 in the $2^{\circ} \mathrm{C}$ scenario (a) Low mobility (b) High mobility

(a)

Scen 2D Low mobility

- Small Car BEV

- Large Car BEV

- Medium CV BEV

- Heavy CV FCEV

- Bus FCEV

$\begin{array}{ll}\text { Small Car PHEV } & \text { Medium Car BEV } \\ \text { Large Car PHEV } & \text { Light CV BEV } \\ \text { Medium CV PHEV } & \text { Heavy CV BEV } \\ \text { Minibus BEV } & \text { Minibus PHEV }\end{array}$
Medium Car PHEV

Light CV PHEV

Heavy CV PHEV

Bus BEV

1200

1000

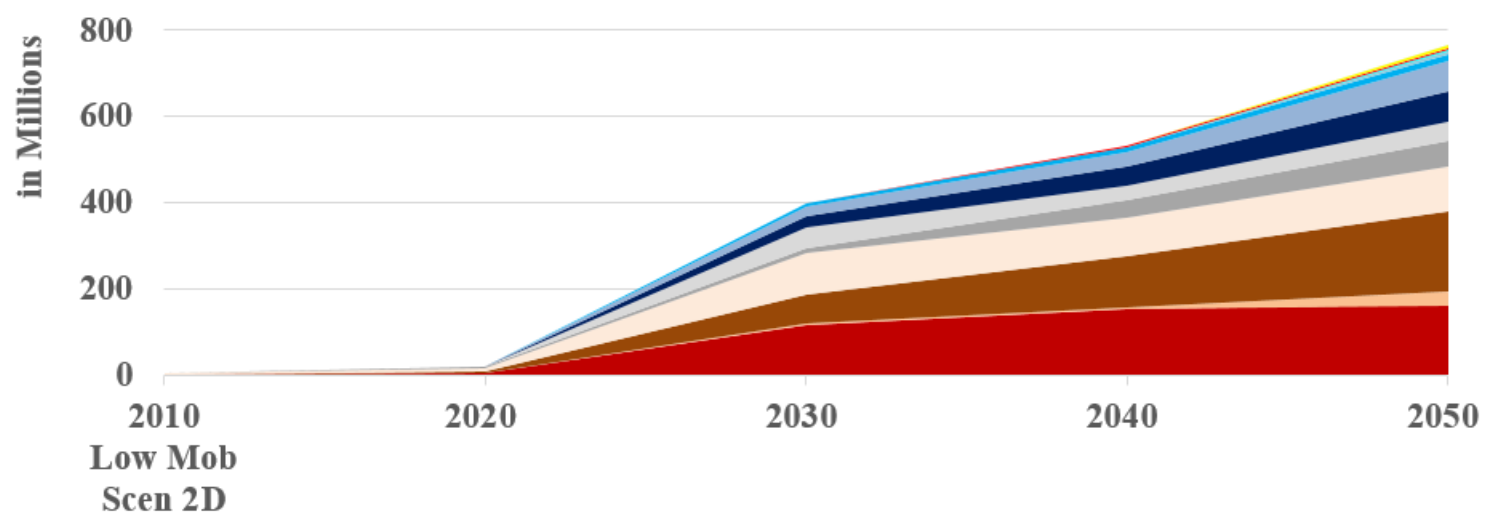

(b)

Scen 2D High mobility

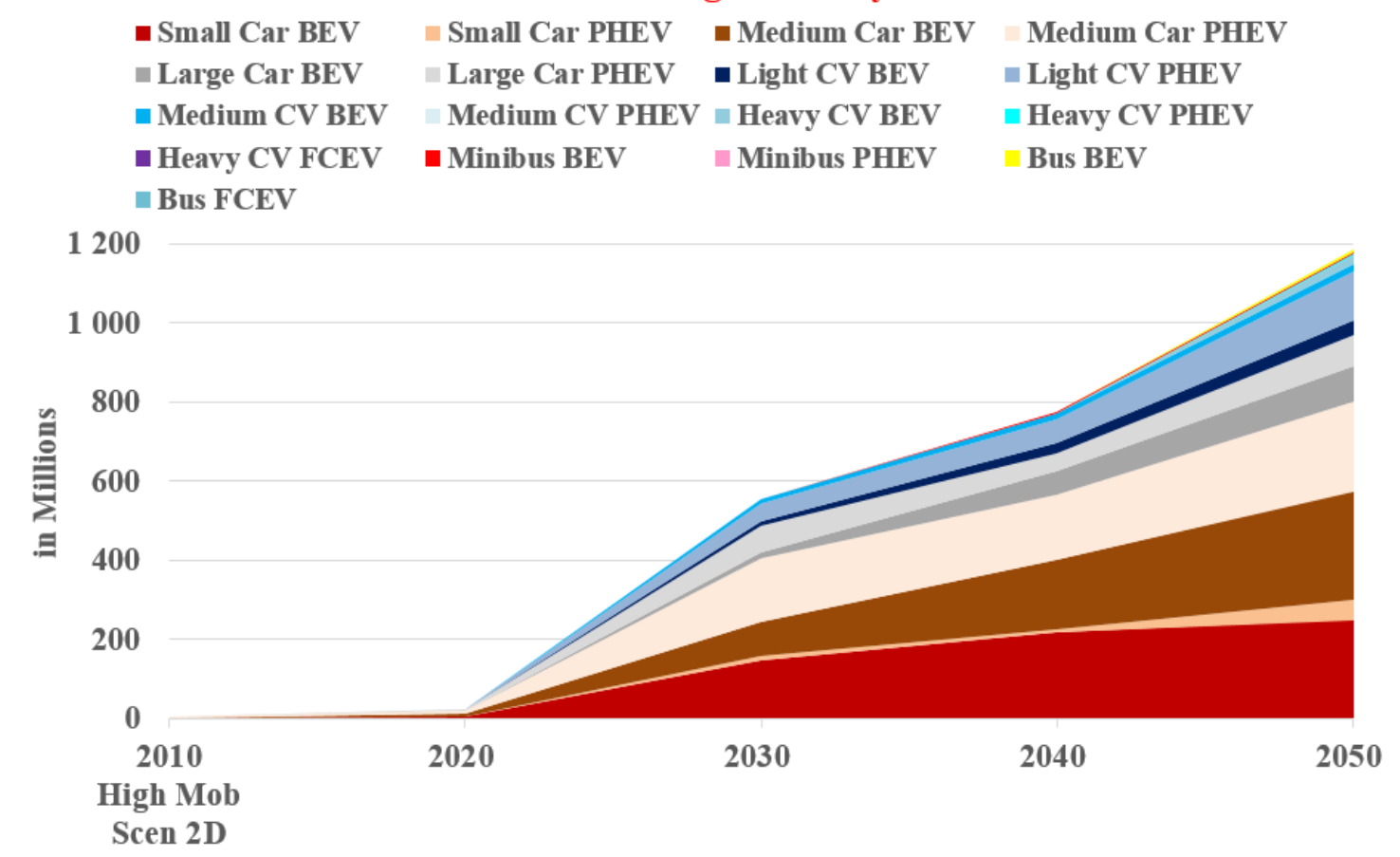

CV: Commercial vehicle 
Our TIAM-IFPEN model could allow us representing in details the evolution of the EV stock by powertrain and by category. We have the example of the $2^{\circ} \mathrm{C}$ scenario with low mobility in Fig. 14 (a) and with high mobility in Fig. 14 (b).

It could be deduced that more than $25 \%$ of EV in circulation by 2050 are small cars (of which around $85 \%$ of battery-powered $\mathrm{EV}$ ) while $40 \%$ and $15 \%$ are respectively medium and large cars. An uptake of the fuel cell electric vehicles (FCEV) has been observed in large cars, heavy commercial vehicles (CV), Minibuses and buses.

Fig. 15 :Evolution of the vehicle's share by category in different power-trains (HEV, PHEV, BEV and FCEV)

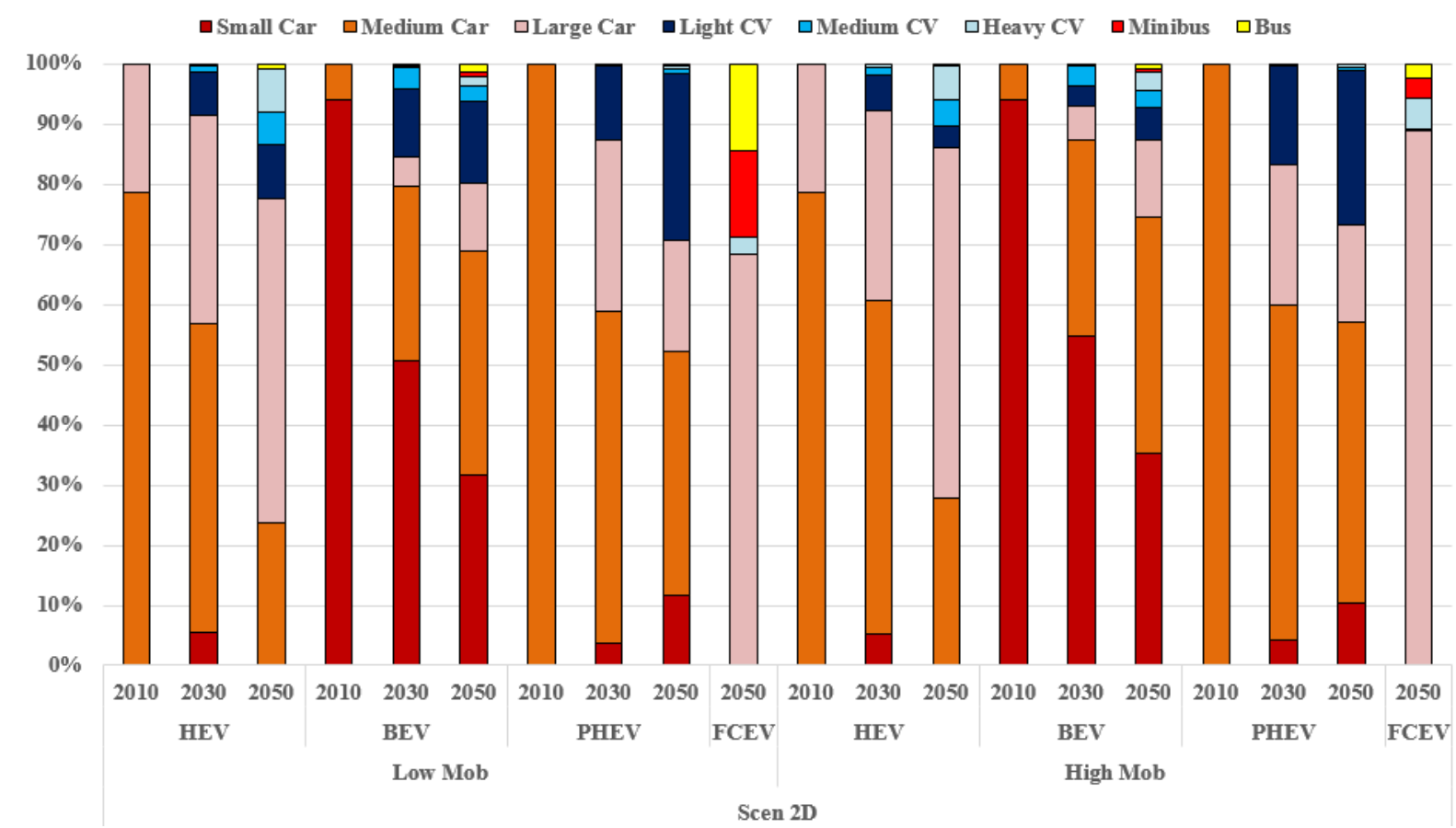

From the outcomes of the model, Fig. 15 displays another representation for a perfect visualisation of the evolution of some power-train uptake (Full hybrid HEV, Plug-in hybrid PHEV, Battery-powered electric vehicle BEV and Fuel cell electric vehicle FCEV) in each category over the time horizon in the $2^{\circ} \mathrm{C}$ scenario. Considering for example the batterypowered EV in the low mobility hypothesis, $95 \%$ of them were small cars category and 5\% in medium size in 2010. However, from 2030, the penetration of EV in medium, large cars, light and medium commercial vehicles is observed. It could be explained by their higher usage and travel demand than small cars (Fig. 11). Therefore, these categories will need more lowemitter vehicles such as electric-powered vehicles with stringent climate scenarios.

\subsection{Impact of the electrification of the transport sector on lithium demand}


Fig. 16 shows the evolution of lithium demand according to each scenario described (4D scenario High Mobility, 4D scenario Low Mobility, 2D scenario Low Mobility, and 2D scenario Low Mobility).

Fig. 16: Evolution of lithium demand from 1990 to 2050 (historical data until 2016)

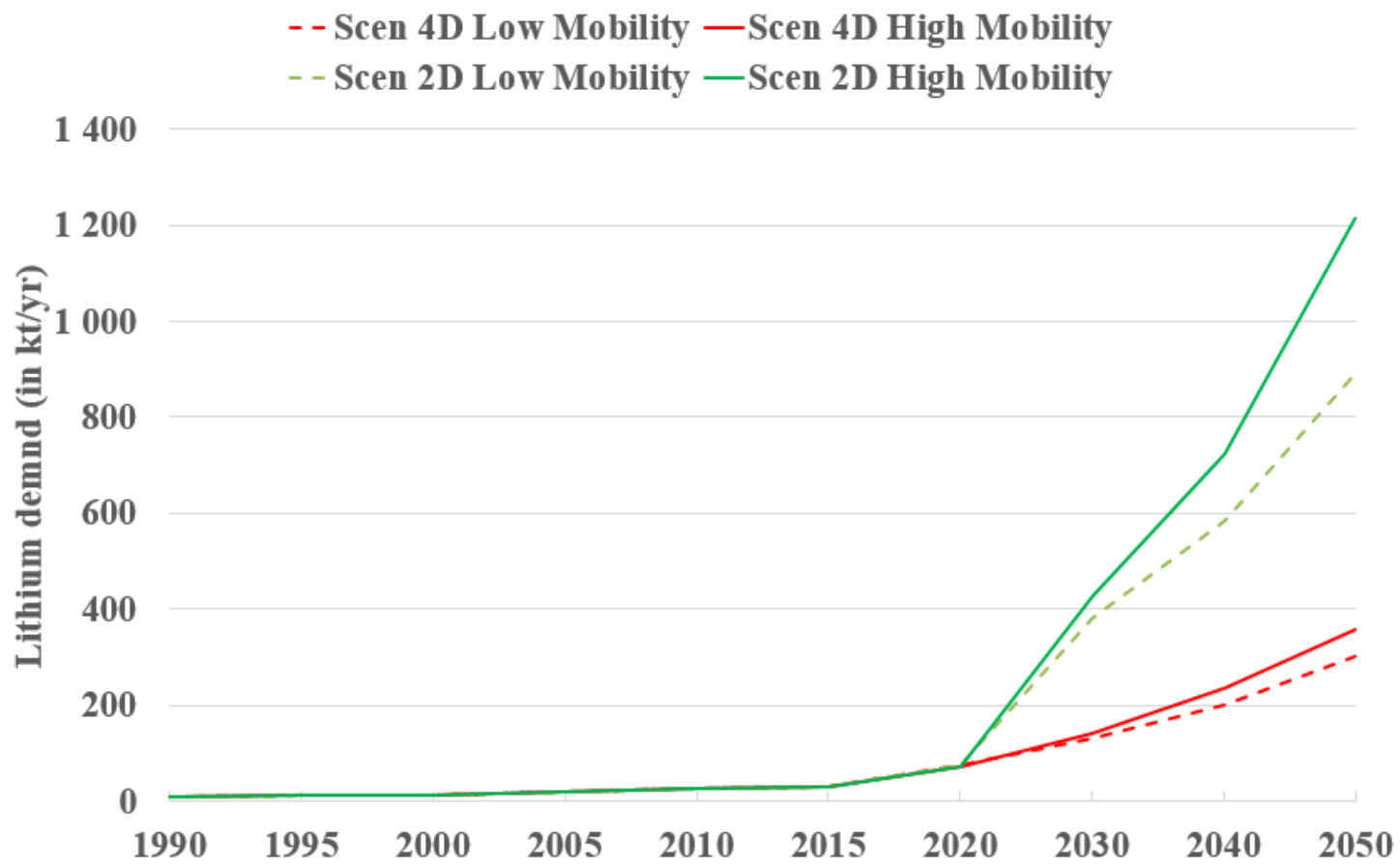

Unsurprisingly the lithium demand is higher in the most constrained climate scenarios where EV stock is higher in order to limit GES emissions, and therefore the global warming to $2{ }^{\circ} \mathrm{C}$.

Fig. 17 : World lithium production per year and per country (left axis) and global world reserve (right axis)
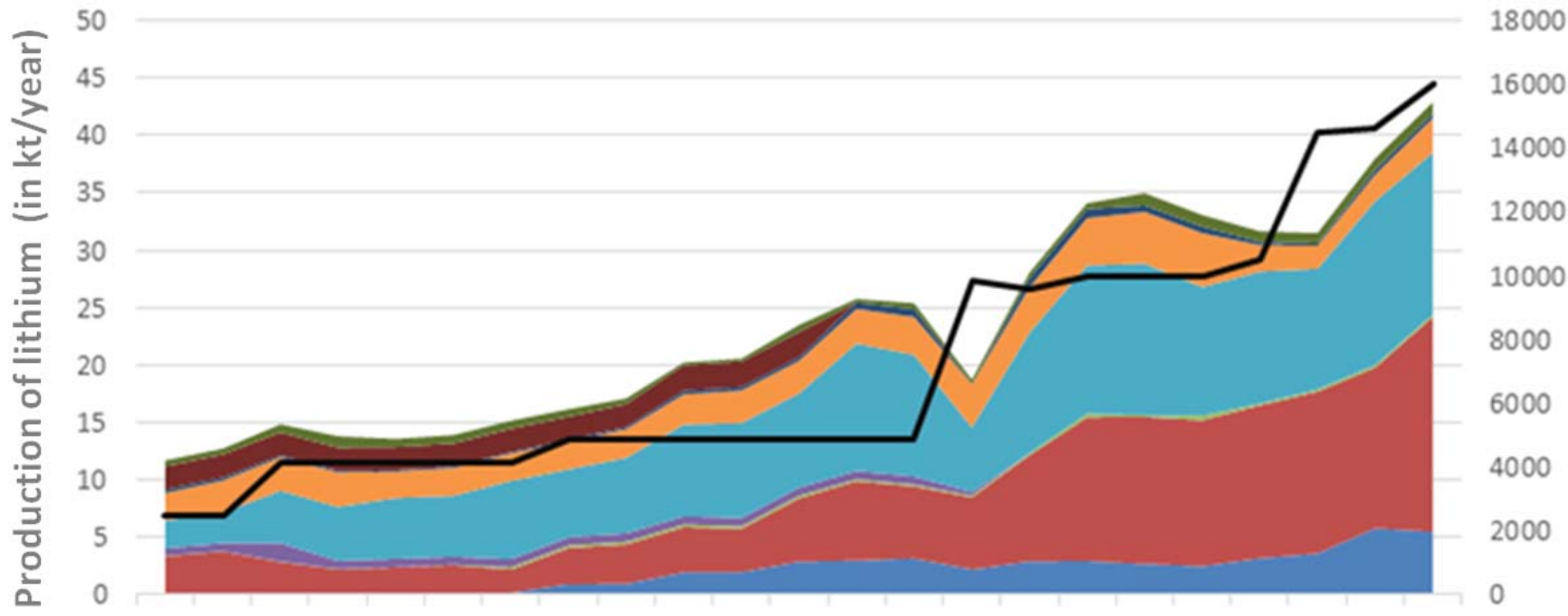

14000

12000

10000

8000

6000

4000

2000

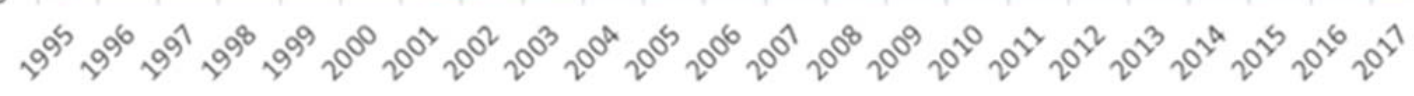

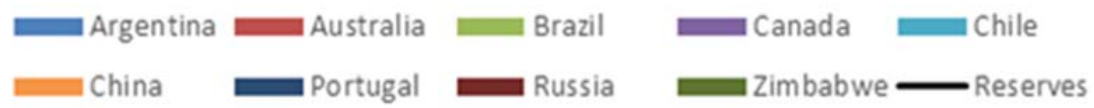

Source: USGS, 2018 
In the $2^{\circ} \mathrm{C}$ scenario with high mobility, the annual lithium production reaches around $1200 \mathrm{kt}$ by 2050 while it is lesser in the case of a lower mobility at around $890 \mathrm{kt}$. Thus, the annual production by 2017 which is around $45 \mathrm{kt}$ (Fig. 17), has been multiplied by 27 and 20 respectively. In the case of the $4^{\circ} \mathrm{C}$ scenarios, the expected annual production is obviously lesser than in the $2^{\circ} \mathrm{C}$, regardless of the shape of mobility considered. Indeed, it increases as high as $300 \mathrm{kt}$ by 2050 in the lower mobility while it is at around $360 \mathrm{kt}$ with a high mobility assumption.

Cumulative demand for lithium from 2005-2050 is estimated at 7.5 and 8.5 Mt respectively in the low and high mobility of the $4^{\circ} \mathrm{C}$ scenario, while it reaches 19.7 and $24.7 \mathrm{Mt}$ in the case of the $2{ }^{\circ} \mathrm{C}$ scenario (Fig. 18). Demand is driven globally by China, Europe, India and USA in both climate scenarios. They have respective shares estimated as high as at approximately $45 \%, 13.5 \%, 12 \%, 9 \%$ of total cumulated consumption in the $4^{\circ} \mathrm{C}$ scenario. High consumption by China is due to the big proportion of two and three-wheelers in addition to PLDVs. In the $2^{\circ} \mathrm{C}$ scenario, the share of China decreases due to more transport electrification in other regions of the world. It is observed that the share of China, Europe, India and USA reach respectively $26 \%, 16.5 \%, 8.5 \%$ and $15 \%$.

\section{Fig. 18: Comparison between the cumulated lithium consumption (2005-2050) and the world lithium resources in 2017}

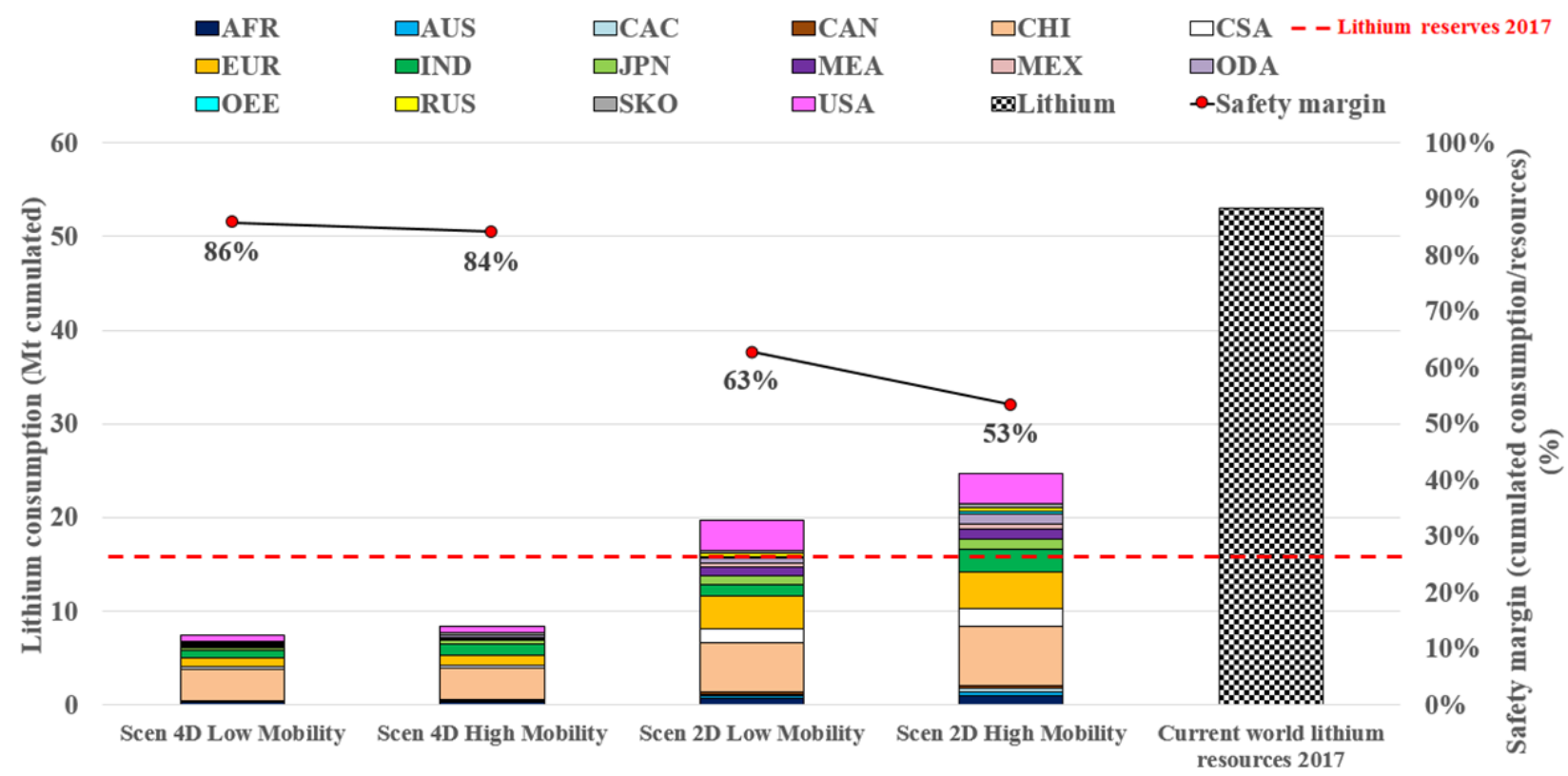

A comparison of cumulative lithium consumption between 2005 and 2050 with current reserves (16 Mt in 2017) provides information about the level of criticality of lithium. Fig. 18 shows that only $2^{\circ} \mathrm{C}$ scenarios will certainly have a cumulative lithium consumption higher 
than the current level of lithium reserves (red dotted line). On the contrary, in the $4^{\circ} \mathrm{C}$ for any shape of mobility, the cumulated lithium demand is far under the current dotted lines representing the lithium reserves 2017.

The safety margin (ratio of the cumulative consumption to the current resources) is decreasing in both climate scenarios as the lithium consumption follow the same trend as the penetration of EV. It fluctuates from $86 \%$ to $84 \%$ in the $4{ }^{\circ} \mathrm{C}$ scenario according to the shape of mobility while it is falling from $63 \%$ to $53 \%$ in the most stringent climate scenario $\left(2{ }^{\circ} \mathrm{C}\right.$ scenario).

A significant share of the current and new resources could become profitable in the future, and therefore be taken into account as reserves, according to technological advances and new processes as well as higher prices on the market. Regarding brines, process optimizations focus on the evaporation step which is expensive and weather constrained in addition to long recovery times (up to 18 months, low yields (40/50\%) and huge negative landscape impact). New processes would extract directly lithium from the brines (see projects conducted by ERAMET or POSCO, etc.). Geothermal brines resources in the United States for instance could be explored in more depth when direct recovery of lithium technologies will be commercialized suggesting new deposits exploitable. Recent research at Stanford has also shown that lake sediments could host large lithium-rich clay deposits ${ }^{18}$.

With regard to resources, new exploration missions could lead to new deposits discovery and increasing resource volumes, especially for non-conventional resources (geothermal brines, clay, mica, etc.) which represent only about $10 \%$ of resources today (USGS, BRGM). Along with these unconventional land-resources, oceans also constitute a natural lithium resource. The lithium concentration is $0.18 \mathrm{mg} / \mathrm{l}$ which would represent an estimated resource between 231 billion tons [77] and 260 billion tons of lithium [78]. Early projects were initiated in the 1970s (USGS) concluding on the technical feasibility but at a much higher cost than lithium current prices. Indeed it is necessary to handle very important volumes of water which requires a considerable energy. The cost of recovering lithium via the oceans has been estimated between $\$ 15$ and $\$ 22$ per kilo of carbonate lithium [42], which is tenfold the cost of production of the Atacama's salar (Chile).

\subsection{Uncertainties on lithium supply despite adequate resources}

Increasing lithium prices can make some resources affordable. Between 2014 and 2017, lithium carbonate prices more than double from $4.90 \$ / \mathrm{kg}$ to $10.60 \$ / \mathrm{kg}$ in average (IHS Markit 2018), stimulating the mining sector and promoting new feasibility studies. In the same period, the reserves have increased by more than $50 \%$ (Fig. 17).

\footnotetext{
${ }^{18}$ https://news.stanford.edu/2017/08/16/supervolcanoes-key-americas-electric-future/
} 
Fig. 19: The evolution of the ratio $R / P$ (reserves/Production) according to four assumptions: (a) $4^{\circ} \mathrm{C}$ scenarios (b) $2^{\circ} \mathrm{C}$ scenarios.

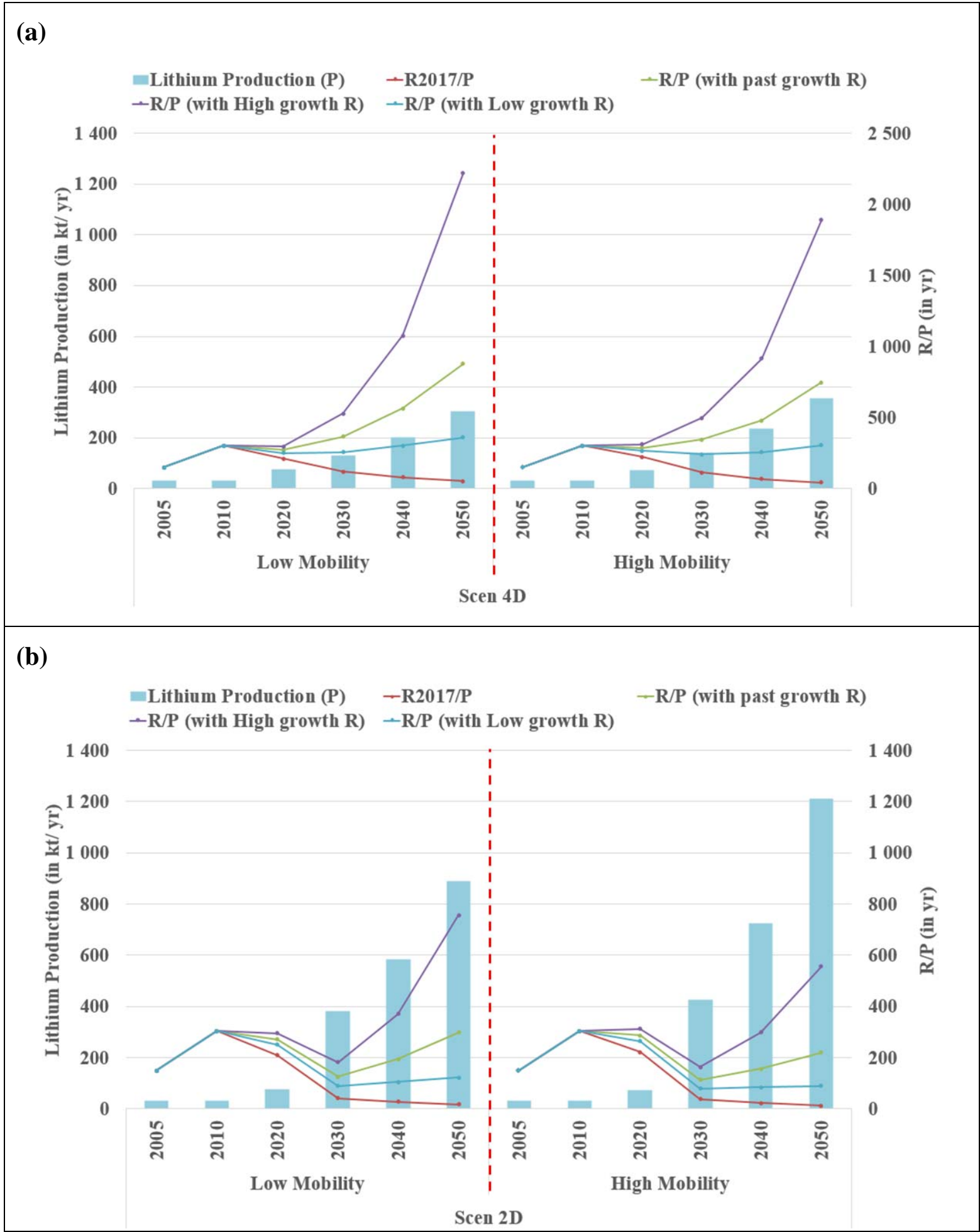

The analysis of the evolution of the Reserves-to-Production ratio could be also interesting retrieving the annual production, an outcome of the model, over the time horizon (Fig. 19). In this graph, we have represented the annual lithium production $(\mathrm{P})$ and thus different Reservesto-Production ratios according to growth rate of the reserves' level: 
- R2017/P is the ratio where it is assumed that the reserves if kept at its level of 2017 and constant onwards $(16 \mathrm{Mt})$. It means that it is the most pessimistic case where the level of reserves would no longer increase from 2017 to 2050.

- $\quad \mathrm{R} / \mathrm{P}$ (with past growth $\mathrm{R}$ ): an assumption of an annual growth rate of the reserves between 2017-2050 is assumed equal to the historic growth rate between 1995-2017, which is $8.9 \% / y r$. It could be considered as the "Business-As-Usual".

- $\quad \mathrm{R} / \mathrm{P}$ (with high growth $\mathrm{R}$ ) and R/P (with low growth $\mathrm{R}$ ): in these two scenarios, it is assumed two annual growth rate of the reserves defined by taking the growth rate of the $\mathrm{R} / \mathrm{P}$ (with past growth $\mathrm{R}$ ) as median. The high growth rate is considered at $12 \% / \mathrm{yr}$ and the low growth rate at $6 \% / y r$ between $2017-2050$

These ratios provide thus the remaining amount of lithium, expressed in time (year). For example in Fig. 19 (b), in the case of a $2^{\circ} \mathrm{C}$ scenario, it is observed that only 18 years remains by 2050 with a low mobility in the pessimistic scenario (R2017/P) while it could increase as high as 760 years in the highest annual growth rate of reserves (R/P high growth $\mathrm{R})$. On the contrary, it is decreasing to 555 years when considering a high mobility and a Reserves-toProduction ratio with a fast growth of the reserves over the time horizon. This analysis is pinpointing the importance of the future exploration and production lead times.

These analyses tend to show that no significant geological risk exists in the lithium market since, as with reserves, resources are substantial (around $52 \mathrm{Mt}$ ) and it is likely that they will be technologically accessible by 2050, at least in part. In the short term, it is important to have time to react between supply and demand, which could may be led to supply risks.

If some lithium mines can be extended and increase their production rate in the near future, new ones have to be implemented to meet the long term demand. When looking to the traditional schedule and steps prior to the production of a lithium mining deposit the entire process could take up to 10 years. Resource identification, exploration and then feasibility analysis could take few years as exploration companies have to raise capital for each steps. Negotiations are then initiated with the government and the population to determine the administrative terms and ensure the acceptability of a future mining project. In addition, a mine can be reached its ramp-up and be fully operated within 1 or 2 years. The investment cost for such projects is high and there are a lot of uncertainties over such long project durations. It is not uncommon for companies to go bankrupt before they have even completed feasibility studies.

As of today, taking into account announcements by mining companies, a dozen new deposits were expected to be mined in 2018. In the short terms, there is significant uncertainty surrounding production lead times, which are typically delayed for several years following producers' announcements. According to the figures announced by the new companies (based 
on 2016 annual reports), it would be between 65 and $85 \mathrm{kt}$ of additional lithium which would be likely to arrive on the market between 2017 and 2020. Given the production published by the USGS in the year 2017 (45 kt of lithium) it could then already represent a threefold increase of production by the end of the decade. From the actors' point of view, most of the credible projects announced exceed $15 \mathrm{kt} \mathrm{LCE}^{19} /$ year and are partly supported by juniors such as Lithium Americas, Orocobre or Galaxy Resources. Having a look to the past production planned and comparing it with effective current volume production leads to large error margins. Moreover, beyond the optimism of companies seeking financing, the volumes thus announced often concern capacity and not production volumes, which tends to overestimate future production.

In addition, in the short term what could be observed is a surplus of lithium ores and concentrates on the market due to a refining bottleneck thereafter if plants are already working at full capacity. Therefore, a reaction time between supply and demand would be required to achieve such a production leap.

\subsection{The decisive impact of national strategies}

$55 \%$ of global resources and nearly $50 \%$ of production are currently coming from the lithium triangle, composed of Argentina, Bolivia and Chile (USGS, 2017).

In Fig. 20, according to the results displayed, it can be observed that this region (Central and South America) will still be the largest exporter of lithium by 2050 . However, national strategies currently vary significantly from one country to another in this region.

In Chile, deposit concession holders are subject to exploitation quotas and short-term leasing contracts. In Argentina, President Mauricio Macri's current economic policy in favour of foreign direct investment (FDI) raises questions about the sustainability of projects, in a country where foreign economic involvement is a national concern that shifts with political change.

Bolivia is a unique case in the commodities market: it has the world's largest lithium resources, located in the Uyuni salt flats, but is not currently producing lithium. Even though there is no real convergence among these three major countries, their national policies are key to understanding the lithium market in the coming years.

\footnotetext{
${ }^{19} \mathrm{LCE}$ : lithium carbonate equivalent. $15 \mathrm{kt}$ LCE equivalent to approximately $3 \mathrm{kt} \mathrm{Li}$
} 
Fig. 20 : Lithium consumption by region, internal production and imports in four major regions: China (CHI), Central and South America (CSA), India (IND), Europe (EUR).

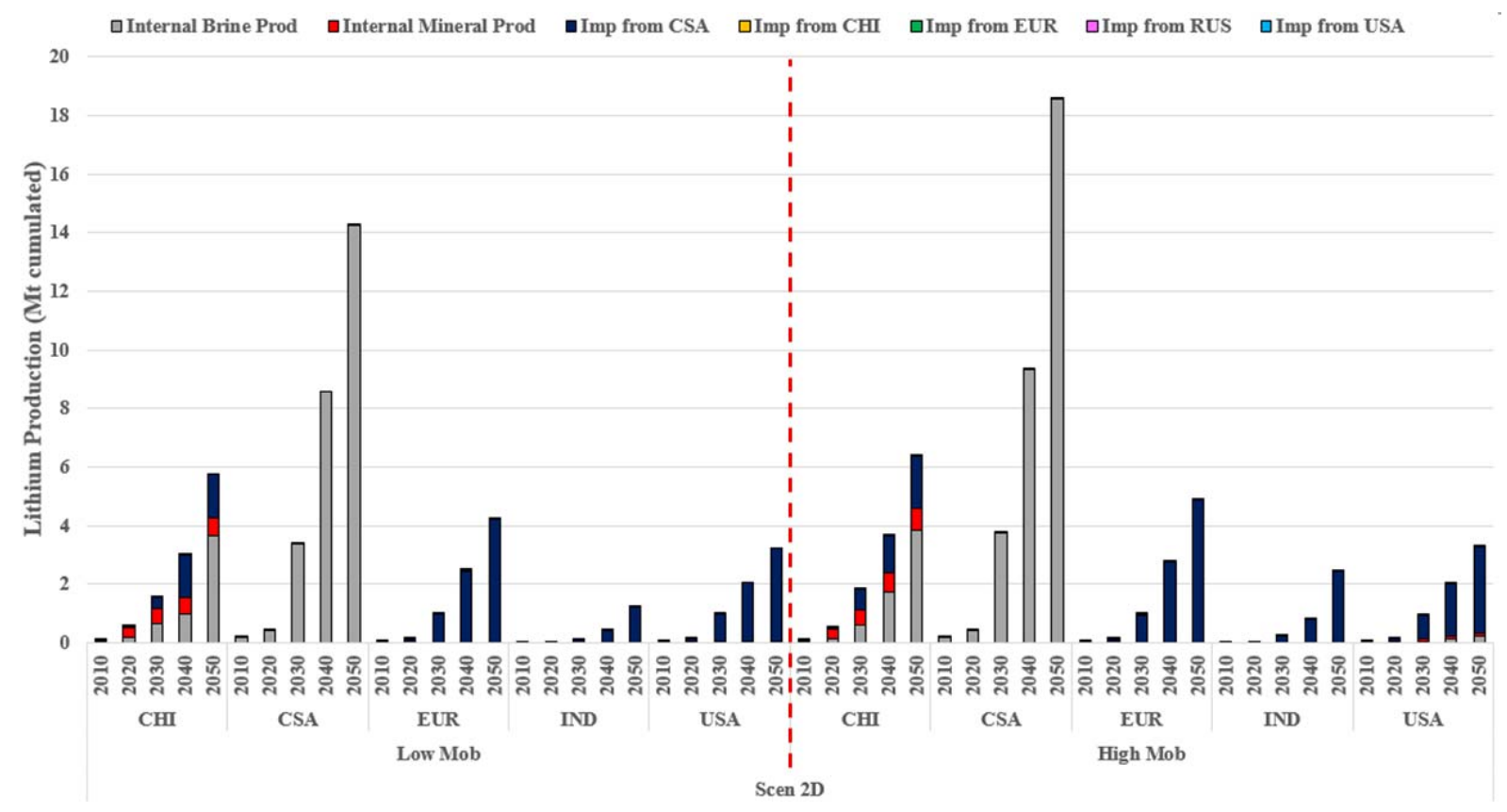

By 2050, Europe, United States, India and China, the other regions in a lesser extent, would become predominantly dependent on imports from the lithium triangle (Fig. 20 \&

Fig. 21). However, China's resources are fairly substantial (around 15\% of global resources), even though their production costs are higher than in the salt flats. China has also completed multiple acquisitions and acquired interests in deposits, both in Australia and in the lithium triangle. China is a net importer of lithium and a net exporter of lithium-based chemicals and processed lithium products (such as lithium cathodes). China imports resources, and refines it within its borders (including $75 \%$ of spodumene from Australia and $25 \%$ of brine from South America). As a major player in the lithium sector with two significant companies, Tianqi Lithium and Ganfeng Lithium Co., Beijing has become the largest consumer of lithium and the largest producer of processed lithium. In this context, changes in Chinese trade policy must be analysed with respect to past transformations observed on other raw material markets (such as rare earths, etc.). 
Fig. 21 : Profile of regionalized lithium imports from the Central and South America (CSA) region

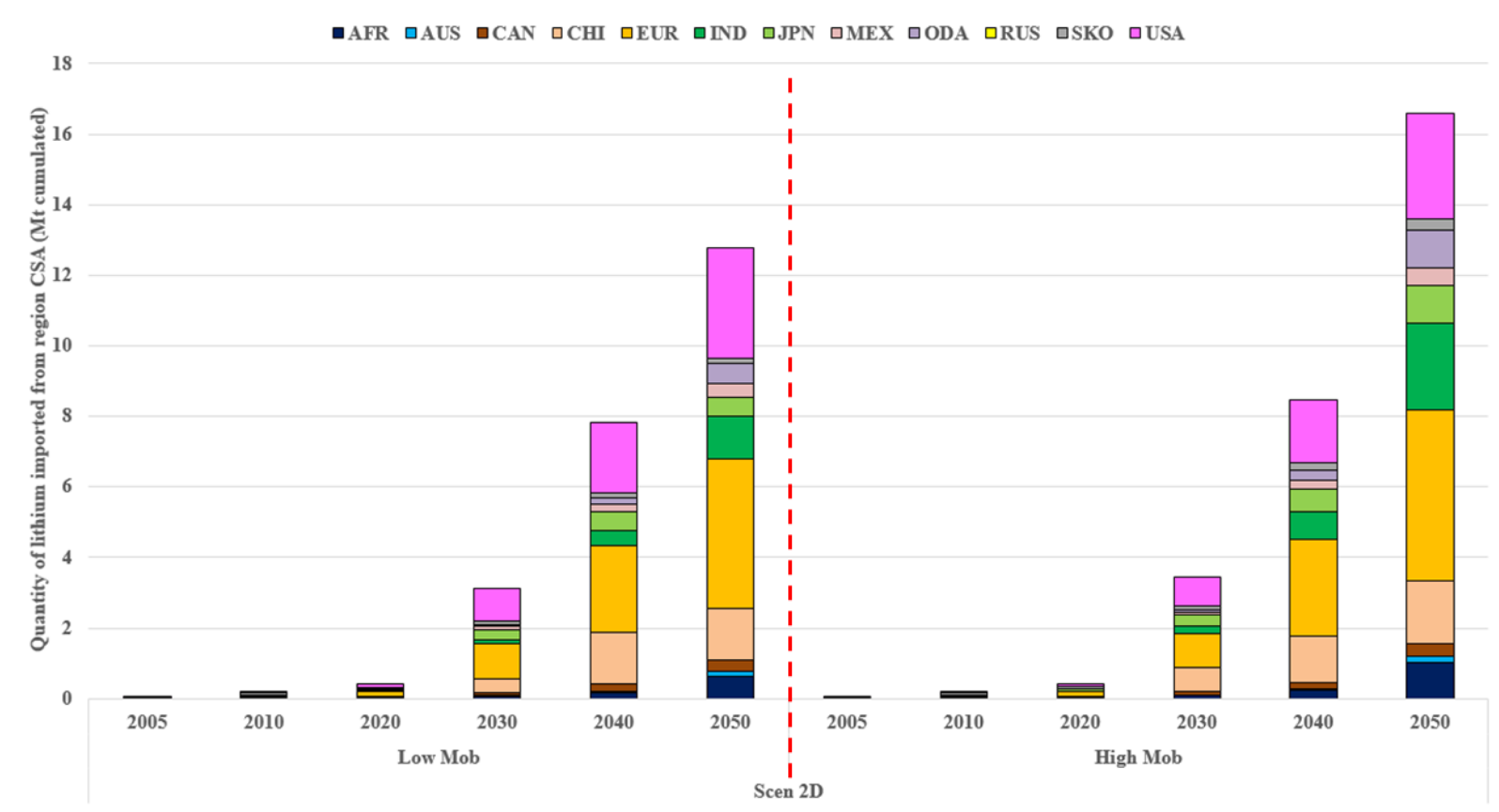

Despite the presence of new players in the exploration sector, the lithium market remains dominated by a few companies, including Chinese companies. Given that instruments used to manage price volatility are not yet available on the commodities markets $(\mathrm{LME})^{20}$, this concentration of players results in major uncertainty about future lithium prices. Price volatility may also weaken newcomers to the market and lead to further consolidation (mergers and acquisitions) among the players. Consolidations may also take place among companies further downstream in the value chain, such as the case of Toyota Tshucho Corp., which invested in the Argentinian company Orocobre Ltd. The lithium market remains small compared with the non-ferrous metal markets ${ }^{21}$. It is characterized by a lack of identified buffer stocks in the markets, which can lead to far more volatile price movements and reduced cyclicality. Shifting demand may therefore lead to sudden reactions by players and high intrinsic volatility on the markets. However, it is important to note the relative role of the price of the commodity lithium in the overall cost of automobile battery manufacturing. Bloomberg ${ }^{22}$ calculated that if the price of lithium tripled, it would only lead to a $2 \%$ increase in battery prices, while the increase would reach nearly $13 \%$ in the case of cobalt.

\footnotetext{
${ }^{20}$ The LME plans to propose new futures contracts including lithium, graphite and manganese (all three used in automobile batteries), starting in January 2019.

${ }^{21}$ Production in the non-ferrous metals market (copper, aluminum, nickel, etc.) totals several Mt.

${ }^{22}$ Bloomberg 2017.
} 


\section{Conclusion}

The number of electric vehicles (two and three-wheelers excluded) on the road reaches between 250 and 360 million units by 2050 in the $4{ }^{\circ} \mathrm{C}$ scenarios, while it is between 760 and 1200 million units in the $2^{\circ} \mathrm{C}$ scenarios according to the type of mobility assumed. In addition, the electric fleet is mostly located in Asian countries (China, India and other developing countries in Asia) due to the large presence of two and three-wheelers that stand for more than half of it. Should the policy ambitions continue to rise to meet climate goals and other sustainability targets, as in the $2^{\circ} \mathrm{C}$ scenario with a high mobility assumption, then the number of electric passenger light-duty vehicles on the road could be as high as 970 million units by 2050 while it would not be more than 310 million units in circulation by 2050 in the $4^{\circ} \mathrm{C}$ scenarios.

The scenarios developed in this article tend to show that a high penetration of the electric vehicles worldwide could lead to a decrease in the lithium safety margin in the $2^{\circ} \mathrm{C}$, the most stringent climate scenario, and an hyper mobility. This leeway varies from $86 \%$ to $84 \%$ respectively in the $4^{\circ}$ Cscenario with low mobility and high mobility while it is falling from $63 \%$ to $53 \%$ in the $2{ }^{\circ} \mathrm{C}$ according to the shape of mobility. Nevertheless, the massive deployment of Li-ion battery technology (small electronics with portable batteries and the first phase of electric vehicle penetration since 2010) has already resulted in a fourfold increase in reserves between 2005 and 2017. The demand of cumulated lithium in the $2{ }^{\circ} \mathrm{C}$ with hyper mobility would reach by 2050 around 1.5 times the current level of lithium reserves. Therefore, it is likely that it will be technologically accessible by 2050 according to recent project announcements. However, long-term equilibrium dynamics in commodity markets tell us that the absence of geological criticality of reserves and resources does not hide different forms of vulnerability, whether economic, industrial, geopolitical or environmental.

Four major risks on the lithium market have been thus identified according to our modelling results:

- Uncertainties about the market's ability to meet the new and growing demand on time

- Uncertainties related to the environmental impacts of lithium production

- Uncertainties about the commercial strategy of large lithium consumers (especially China)

- Uncertainties about the consequences of national strategies in the lithium triangle

Concerning the first point above mentioned there are strong short term uncertainties related in particular to production delays, which are generally several years later than the estimated ramp-ups. As mentioned above, these announced volumes often concern installed capacity and not production volumes, which are likely to overestimate future production. 
The uncertainties related to the environmental impacts of lithium production should also be highlighted. Such future volume production in the lithium triangle could have serious environmental consequences. Beyond the destruction of fauna and flora or the degradation of landscapes, the need for fresh water and energy could be critical. Some lithium extraction and purification processes are water-intensive, which could be a problem due to the water stress already existing around salars and salt lakes.

Despite the presence of many new entrants in the exploration sector, the lithium market is still dominated by a limited number of companies, including the Chinese ones. As there are not any instruments to manage price volatility on commodity exchanges, this concentration of players leads to considerable uncertainty about future lithium prices. However, the London Metal Exchange plans to offer new futures contracts including lithium, graphite and manganese (all three used in automotive batteries) from January 2019. Price volatility could weaken new market entrants and lead to new consolidation movements (mergers and acquisitions) between players.

Given the importance of China in the lithium market, a more in-depth analysis of any changes in China's trade policy (introduction of quotas, embargo) should be made following historical trends in other raw material markets (rare earths, etc.).

Although China owns about around $15 \%$ of world lithium resources, according to our results, it is expected to be highly dependent on supplies from South America (like other global lithium consumers such as the United States of America, India or Europe). The lithium triangle between Argentina, Bolivia and Chile which currently accounts for 55\% of world resources and nearly $50 \%$ of production, should be the largest exporter of lithium by 2050 . In the $2{ }^{\circ} \mathrm{C}$ scenario with more car dependencies, the region could represent about $90 \%$ of the lithium supply. Therefore, current contrasting national strategies within it may constitute future supply uncertainties. In Chile, reservoir concession companies are subject to exploitation quotas, as well as limited-term lease contracts. Argentina is currently very favourable to foreign investments but Foreign Direct Investment (FDI) policies are a national issue which may change with future country governance. In the case of Bolivia which endows one of the most important resources but has not yet started production, the Bolivian government is more in favour of a vertical integration of the local industry to position itself along the entire industrial value chain (including battery production).

As our results show a low risk of criticality which suggests that lithium will not see its price soar and that recycling will be even less attractive. However, the latter conclusion should be made with caution based on regional regulatory constraints related to policy guidelines with lithium resources in a given region. This means that lithium recycling sector could be part of energy security concept as part of a major development of electric vehicles. Other 
perspectives of our global model would then be to implement a supply chain network for electric vehicle battery that will consider remanufacturing and recycling infrastructures. It may also be useful to analyse, on a global scale, the impact of other strategic materials (nonferrous metals such as cobalt, nickel, copper and rare-earth metals such as neodymium, terbium, lanthanum, etc.) either in the transport sector or in the power sector with the increasing penetration rate of renewable energy technologies (RETs). This model could be very valuable as a good decision-making tool for a better anticipation of investments according to the future constraints of the raw material market.

\section{Acknowledgement}

This study received the financial support of the French National Research Agency (ANR) and this article is part of the GENERATE (Renewable Energies Geopolitics and Future Studies on Energy Transition) project. It receives also funding from the French Environment \& Energy Management Agency with a project dedicated to lithium. The authors are very grateful to Amit Kanudia who has contributed to the TIAM-IFPEN model on behalf of his company KANoRS through providing assistance. We are also very grateful to François Kalaydjian and Jerome Sabathier for insightful comments and suggestions. Of course, any remaining errors are ours. The views expressed herein are strictly those of the authors and are not to be construed as representing those of IFP Énergies Nouvelles.

\section{References}

[1] Dechezleprêtre A., Glachant M., Ménière Y., 2008, The Clean Development Mechanism and the international diffusion of technologies: An empirical study, Energy Policy 36, p1273-1283

[2] Bonnet C., Carcanague S., Hache E., Seck G. S., Simoen M., 2019, Vers une géopolitique de l'énergie plus complexe ? Une analyse prospective tridimensionnelle de la transition énergétique, IRIS (The French Institute for International and Strategic Affairs), Policy Research Working Paper, http://www.iris-france.org/wpcontent/uploads/2019/01/Policy-PAPER-GENERATE-janvier-2019.pdf

[3] Jaffe R., Price J., Ceder G., Eggert R., Graedel T., 2011, Energy Critical Elements: Securing Materials for Emerging Technologies, A Report by the APS Panel on Public Affairs \& the Materials Research Society. American Physical Society and the Materials Research Society, Washington, D.C.

[4] Graedel, T.E., 2011, On the Future Availability of the Energy Metals. Annual Review of Materials Research 41, p323-335 
[5] Vidal O., 2018, Matières premières et énergie: les enjeux de demain, Collection Energie, ISTE Editions

[6] Hache E., 2018, "Do renewable energies improve energy security in the long run?", International Economics 156, p127-135

[7] Hache E., 2016, "La géopolitique des énergies renouvelables : amélioration de la sécurité énergétique et / ou nouvelles dépendances ?", Revue Internationale et Stratégique, $\mathrm{n}^{\circ} 101, \mathrm{p} 36-46$

[8] Gleich B., Achzet B., Mayer H., and Rathgeber A., 2013, An empirical approach to determine specific weights of driving factors for the price of commodities - a contribution to the measurement of the economic scarcity of minerals and metals Resources Policy 38, p350-62

[9] National Research Council, 2008, Minerals, Critical Materials And the U.S. Economy, Prepublication Version[Online]; National Academies Press; Washington, DC,2008; https://www.nap.edu/resource/12034/critical_minerals_final.pdf

[10] Graedel, T.E., Harper, E.M., Nassar, N.T., Nuss, P., Reck, B.K., 2015, Criticality of metals and metalloids. Proceedings of the National Academy of Sciences of the United States of America 112, p4257-4262

[11] Erdmann, L., Graedel, T.E., 2011, Criticality of non-fuel minerals: a review of major approaches and analyses. Environ. Sci. Technol. 45, p7620-7630

[12] Achzet, B., Helbig, C., 2013, How to evaluate raw material supply risks - an overview. Resources Policy 38, p435-447

[13] Graedel, T.E., Reck, B.K., 2016, Six years of criticality assessments: what have we learned so far? J. Ind. Ecol. 20, p692-699

[14] Du X., Graedel T.E., 2011, Global In-Use Stocks of the Rare Earth Elements: A First Estimate, Environmental Science \& Technology 45, p4096-4101.

[15] Goonan T. G., 2011, Rare Earth Elements - End Use and Recyclability. Scientific Investigations Report 2011-5094. U.S. Geological Survey, Washington, DC, US.

[16] Golev A., Scott M., Erskine P. D., Ali S. H., Ballantyne G. R., 2014, Rare earths supply chains: Current status, constraints and opportunities, Resources Policy 41, p5259

[17] European Commission, 2017, Assessment of the Methodology for Establishing the EU List of Critical Raw Materials, JRC Technical reports, http://publications.jrc.ec.europa.eu/

[18] Baldi L., Peri M., Vandone D., 2014, Clean Energy Industries and Rare Earth Materials: Economic and financial issues, Energy Policy 66, p53-61. 
[19] Harper E.M., Diao, Z., Panousi, S., Nuss, P., Eckelman, M.J., Graedel, T.E., 2015a. The criticality of four nuclear energy metals. Resources, Conseration and. Recycling 95, p193-201

[20] Harper E.M., Kavlak, G., Burmeister, L., Eckelman, M.J., Erbis, S., Sebastian Espinoza, V., Nuss, P., Graedel, T.E., 2015, Criticality of the geological zinc, tin, and lead family. Journal of Industrial Ecology 19, p628-644

[21] Nassar N.T., Du, X., Graedel, T.E., 2015, Criticality of the rare earth elements. Journal of Industrial Ecology 19, p1044-1054

[22] Bach V., Finogenova N., Berger M., Winter L., Finkbeiner M., 2017, Enhancing the assessment of critical resource use at the country level with the SCARCE method Case study of Germany, Resources Policy 53, p283-299

[23] Hatayama H., Tahara K., 2018, Adopting an objective approach to criticality assessment: Learning from the past, Resources Policy 55, p96-102

[24] Habib K., Hamelin L., Wenzel H., 2016, A dynamic perspective of the geopolitical supply risk of metals, Journal of Cleaner Production 133, p850-858.

[25] Rosenau-Tornow D., Buchholz P., Riemann A., Markus Wagner, 2009, Assessing the long-term supply risks for mineral raw materials - a combined evaluation of past and future trends, Resources Policy 34, p161-175

[26] Buchholz P., Liedtke M., Gernuks M., 2012, Evaluating supply risk patterns and supply and demand trends for mineral raw materials: Assessment of the zinc market, Non-Renewable Resource Issues: Geoscientific and Societal Challenges, International year of Planet Earth

[27] Moss R. L., Tzimas E., Kara H., Willis P., Kooroshy J., 2013, The potential risks from metals bottlenecks to the deployment of Strategic Energy Technologies, Energy Policy 55, p556-564

[28] Roelich K., Dawson D. A., Purnell P., Knoeri C., Revell R., Busch J., Steinberger J. K., 2014, Assessing the dynamic material criticality of infrastructure transitions: A case of low carbon electricity, Applied Energy 123, pp378-386

[29] Beylot A., Guyonnet D., Muller S., Vaxelaire S., Villeneuve J., 2019, Mineral raw material requirements and associated climate-change impacts of the French energy transition by 2050, Journal of Cleaner Production 208, p1198-1205

[30] Boubault A., Kang S., Maizi N., 2018, Closing the TIMES integrated assessment model (TIAM-FR) raw materials gap with life-cycle inventories, Journal of Industrial Ecology, https://doi.org/10.1111/jiec. 12780

[31] Viebahn P., Soukup O., Samadi S., Teubler J., Wiesen K., Ritthoff M., 2015, Assessing the need for critical minerals to shift the German energy system towards a 
high proportion of renewables, Renewable and Sustainable Energy Reviews 49, p655671

[32] García-Gusano D., Iribarren D., Martín-Gamboa M., Dufour J., Espegren K., Lind A., 2016, Integration of life-cycle indicators into energy optimisation models: the case study of power generation in Norway, Journal Cleaner Production 112, p2693-2696

[33] Daly H.E., Scott K., Strachan N., Barrett J., 2015, Indirect $\mathrm{CO}_{2}$ emission implications of energy system pathways: linking IO and TIMES models for the UK. Environmental Science \& Technology 49, p10701-10709.

[34] McDowall, W., Solano Rodriguez B., Usubiaga A., Acosta Fernández J., 2018, Is the optimal decarbonization pathway influenced by indirect emissions? Incorporating indirect life-cycle carbon dioxide emissions into a European TIMES model. Journal of Cleaner Production 170, p260-268

[35] Graedel, T.E., Barr, R., Chandler, C., Chase, T., Choi, J., Christoffersen, L.,Friedlander, E., Henly, C., Jun, C., Nassar, N.T., Schechner, D., Warren, S., Yang, M., Zhu, C., 2012, Methodology of metal criticality determination. Environ. Sci. Technol. 46, p1063-1070

[36] Helbig, C., Wietschel, L., Thorenz, A., Tuma, A., 2016, How to evaluate raw material vulnerability, An overview. Resources Policy 48, p13-24.

[37] International Energy Agency IEA, 2018, Global EV Outlook 2018: towards crossmodel electrification.

[38] Hache E., Seck G. S., Simoen M., 2018, Electrification du parc automobile mondial et criticité du lithium à l'horizon 2050, Technical report, ADEME (French Environment \& Energy Management Agency)/IFPEN (IFP Energies Nouvelles), In Press

[39] Vikström H., Davidsson S., Höök M., 2013, Lithium availability and future production outlooks, Applied Energy 110, p252-266

[40] Grosjean C., Miranda P. H., Perrin M., Poggi P., 2012, Assessment of world lithium resources and consequences of their geographic distribution on the expected development of the electric vehicle industry, Renewable and Sustainable Energy Reviews 16, pp1735-1744

[41] Martin G., Rentsch L., Höck M., Bertau M., 2017, Lithium market research - global supply, future demand and price development, Energy Storage Materials 6, p171-179.

[42] Yaksic, A., Tilton J., 2009, Using the cumulative availability curve to assess the threat of mineral depletion: The case of lithium, Resources Policy 34, p185-194. 
[43] Speirs J., Contestabile M., Houari Y., Gross R., 2014, The future of lithium availability for electric vehicle batteries, Renewable and Sustainable Energy Reviews 35, p183-193.

[44] Ziemann S., Müller D. B., Schebek L., Weil M., 2018, Modeling the potential impact of lithium recycling from EV batteries on lithium demand: A dynamic MFA approach, Resources Conservation And Recycling 133, p76-85.

[45] Zeng X., Li J., Liu L., 2015, Solving spent lithium-ion battery problems in China: Opportunities and challenges, Renewable and Sustainable Energy Reviews 52, p17591767.

[46] Helbig C., Bradshaw A. M., Wietschel L., Thorenz A., Tuma A., 2018, Supply risks associated with lithium-ion battery materials, Journal of Cleaner Production 172, p274-286

[47] Wang X., Gaustad G., Babbitt C. W., Richa K., 2014a, Economies of scale for future lithium-ion battery recycling infrastructure, Resources Conservation and Recycling 83, p53-62

[48] Sun X., Hao H., Zhao F., Liu Z., 2017, Tracing global lithium flow : A trade-linked material flow analysis, Resources, Conservation \& Recycling 214, p50-61.

[49] Hao H., Liu Z., Zhao F., Geng Y., Sarkis J., 2017, Material flow analysis of lithium in China, Resources Policy 51, p100-106.

[50] Kohl B., Farthing L., 2012, Material constraints to popular imaginaries: The extractive economy and resource nationalism in Bolivia, Political Geography 31, p225-235

[51] Bates, J., 2016, An Evaluation of the Lithium Mining Environment in South America.Mining.com (June 14).

[52] Zeng X., Li J., 2013, Implications for the carrying capacity of lithium reserve in China, Resources, Conservation and Recycling 80, p58-63.

[53] Miedema J. H., Moll H. C., 2013, Lithium availability in the EU27 for battery-driven vehicles: The impact of recycling and substitution on the confrontation between supply and demand until 2050, Resources Policy 38, p204-211

[54] Loulou R., Remme U., Kanudia A., Lehtila A., Goldstein G., 2016, Documentation for the TIMES model, ETSAP (www.etsap.org).

[55] Gargiulo M., Getting started with TIMES VEDA, Version 2.7, May 2009, https://ieaetsap.org/index.php/documentation

[56] Fishbone L.G., Giesen G., Goldstein G., Hymmen H.A., Stocks K.J., Vos H., Wilde D., Zölcher R., Balzer C., Abilock H., 1983, User.s Guide for MARKAL (BNL51701), Brookhaven National Laboratory, Upton, New York. 
[57] Loulou R., Kanudia A., 1997, The MARKAL family of Models: Relevance to Global Environmental Analysis, Proc. of the CERI Environment-Energy Modelling Forum, Ottawa, Oct. 14-16, 1997 KANORS (www.kanors.com).

[58] Loulou R., Goldstein G., Noble K., 2004, Documentation for the MARKAL family models, ETSAP (www.etsap.org).

[59] Van der Voort E., Donni E., Thonet C., Bois d'Enghien E., Dechamps C., Guilmot J.F.,1984, Energy Supply Modelling Package EFOM-12C, Mark 1. CABAY, Belgium

[60] Loulou, R., Labriet, M., 2008, ETSAP-TIAM: the TIMES integrated assessment model Part I: Model structure, Computational Management Science, Volume 5, Issue 1-2, pp. 7-40, DOI 10.1007/s10287-007-0046-z.

[61] Lechon Y., Cabal H., Varela M., Saez R., Eherer C., Baumannb, M., Duweke J. Hamacherc, T. and Tosato G., 2005, A global energy model with fusion, Fusion Engineering and Design. 75-79, p1141-1144

[62] Vaillancourt, K., Labriet, M., Louloua, R., and Waaub, J. 2008, The role of nuclear energy in long-term climate scenarios: An analysis with the World-TIMES model, Energy Policy 36, p2296-2307

[63] Gracceva F., Zeniewski P., 2013, Exploring the uncertainty around potential shale gas development-A global energy system analysis based on TIAM (TIMES Integrated Assessment Model), Energy 57, p443-457.

[64] Selosse S., Ricci O., 2014, Achieving negative emissions with BECCS (bioenergy with carbon capture and storage) in the power sector: New insights from the TIAM-FR (TIMES Integrated Assessment Model France) model, Energy 76, p967-975.

[65] Van der Zwaan, B., Keppo, I., Johnsson, F., 2013. How to decarbonize the transport sector?, Energy Policy 61, p562-573.

[66] Anandarajah G., McDowall W., Ekins P., 2013, Decarbonising road transport with hydrogen and electricity: Long term global technology learning scenarios, international journal of hydrogen energy 38, p3419-3432

[67] International Energy Agency IEA, 2016, World Energy Outlook 2016.

[68] International Renewable Energy Agency IRENA, 2018, Renewable Power Generation Costs in 2017

[69] Schimpf S., Sturm F., Correa V., Bodo B., Keane C., 2017, The word of raw materials 2050: scoping future dynamics in raw materials through scenarios,. Energy Procedia 125, p6-13

[70] Remme U., Blesl M., Fahl U., 2007, Global resources and energy trade : An overview for coal, natural gas, oil and uranium, Institut für Energiewirtschaft und Rationelle Energieanwendung (IER). 
[71] Hache E., Seck G. S., Simoen M., 2018c, What is the level of criticality of lithium for electrification of the global automobile fleet?, Fiche Panorama IFPEN (IFP Energies Nouvelles), In Press

[72] Li L., Dababneh F., Zhao J., 2018, Cost-effective supply chain for electric vehicle battery remanufacturing, Applied Energy 226, p277-286

[73] Diao M, 2018, Towards sustainable urban transport in Singapore: Policy instruments and mobility trends, Transport policy, https://doi.org/10.1016/j.tranpol.2018.05.005

[74] UN-Habitat, 2013, Planning and design for sustainable urban mobility: Global report on human settlements 2013.

[75] Santos G., Behrendt H., Teytelboym A., 2010, Part II: Policy instruments for sustainable road transport, Research in Transportation Economics 28, p46-91

[76] Goletz M., Feige I., Heinrichs D., 2016, What drives mobility trends: results from case studies in Paris, Santiago de Chile, Singapore and Vienna, Transportation Research Procedia 13, p49-60.

[77] Bardi U., 2010, Extracting Minerals from Seawater: An Energy Analysis, Sustainability 2, p980-992

[78] Mero J.L., 1965, The Mineral Resources of the Sea, Elsevier Science 